\title{
Pharmacological Blockade of PPAR $\alpha$ Exacerbates Inflammatory Pain-Related Impairment of Spatial Memory in Rats
}

\author{
Jessica C. Gaspar ${ }^{1,2,3}$, Catherine Healy ${ }^{1,2,3}$, Mehnaz I. Ferdousi ${ }^{1,2,3}$, Michelle Roche ${ }^{2,3,4}$ (D) \\ and David P. Finn $1,2,3, * \mathbb{B}$ \\ 1 Pharmacology and Therapeutics, National University of Ireland Galway, H91 W5P7 Galway, Ireland; \\ jeccgaspar@gmail.com (J.C.G.); c.healy22@nuigalway.ie (C.H.); m.ferdousi1@nuigalway.ie (M.I.F.) \\ 2 Galway Neuroscience Centre, National University of Ireland Galway, H91 W5P7 Galway, Ireland; \\ michelle.roche@nuigalway.ie \\ 3 Centre for Pain Research, National University of Ireland Galway, H91 W5P7 Galway, Ireland \\ 4 Physiology, National University of Ireland Galway, H91 W5P7 Galway, Ireland \\ * Correspondence: david.finn@nuigalway.ie; Tel.: +353-091-495280
}

Citation: Gaspar, J.C.; Healy, C.; Ferdousi, M.I.; Roche, M.; Finn, D.P. Pharmacological Blockade of PPAR $\alpha$ Exacerbates Inflammatory Pain-Related Impairment of Spatial Memory in Rats. Biomedicines 2021, 9 , 610. https://doi.org/10.3390/ biomedicines 9060610

Academic Editor: Annamaria Cimini

Received: 30 April 2021

Accepted: 26 May 2021

Published: 27 May 2021

Publisher's Note: MDPI stays neutral with regard to jurisdictional claims in published maps and institutional affiliations.

Copyright: (c) 2021 by the authors. Licensee MDPI, Basel, Switzerland. This article is an open access article distributed under the terms and conditions of the Creative Commons Attribution (CC BY) license (https:/ / creativecommons.org/licenses/by/ $4.0 /)$.

\begin{abstract}
Peroxisome proliferator-activated receptors (PPARs) are ligand-dependent transcription factors that exist in three isoforms: PPAR $\alpha, \operatorname{PPAR} \beta / \delta$ and PPAR $\gamma$. Studies suggest that the PPAR signalling system may modulate pain, anxiety and cognition. The aim of the present study was to investigate whether endogenous signalling via PPARs differentially modulates innate anxiety responses and mnemonic function in the presence and absence of inflammatory pain. We examined the effects of intraperitoneal administration of GW6471 (PPAR $\alpha$ antagonist), GSK0660 (PPAR $\beta / \delta$ antagonist), GW9662 (PPAR $\gamma$ antagonist), and N-palmitoylethanolamide (PEA) on rat behaviour in the elevated plus maze (EPM), open field (OF), light-dark box (LDB), and novel object recognition (NOR) tests in the presence or absence of chronic inflammatory pain. Complete Freund's Adjuvant (CFA)-injected rats exhibited impaired recognition and spatial mnemonic performance in the NOR test and pharmacological blockade of PPAR $\alpha$ further impaired spatial memory in CFA-treated rats. $N$-oleoylethanolamide (OEA) levels were higher in the dorsal hippocampus in CFA-injected animals compared to their counterparts. The results suggest a modulatory effect of CFA-induced chronic inflammatory pain on cognitive processing, but not on innate anxiety-related responses. Increased OEA-PPAR $\alpha$ signalling may act as a compensatory mechanism to preserve spatial memory function following CFA injection.
\end{abstract}

Keywords: peroxisome-proliferator activated receptor; cognition; anxiety; spatial memory; complete Freund adjuvant; PEA; OEA; dorsal hippocampus

\section{Introduction}

Peroxisome proliferator-activated receptors (PPARs) are ligand-dependent transcription factor members of the nuclear hormone superfamily of receptors. There are three PPAR isoforms: PPAR $\alpha, \operatorname{PPAR} \beta / \delta$ and PPAR $\gamma$ [1]. Endogenous ligands at PPARs include fatty acids [2] and N-acylethanolamines (NAEs) such as anandamide (AEA) [3,4], $N$-palmitoylethanolamide (PEA) [5], and $N$-oleoylethanolamide (OEA) [6]. PPARs are involved in a diverse array of physiological processes and are drug targets for treating diabetes [7] and dyslipidemia [8]. Moreover, studies suggest that the PPAR signalling system may modulate pain [9], anxiety [10] and cognition [11-15]. PPARs also regulate inflammatory processes and PPAR agonists have anti-inflammatory effects in models of chronic inflammation $[16,17]$.

While there are some important differences between the PPAR subtypes in terms of tissue expression, endogenous and synthetic ligands and physiological roles, all three subtypes of PPARs are expressed in brain regions that are commonly implicated in pain, anxiety and cognition such as the amygdala [18], PFC [18-20], hippocampus [10,19] and 
periaqueductal grey (PAG) [21]. However, few studies have investigated the role of PPARs in anxiety and cognition. Endogenous ligands at PPARs have been shown to be increased in response to stress or anxiety [22,23]. Meanwhile, levels of OEA are significantly lower in patients with post-traumatic stress disorder (PTSD) compared to controls [24]. Additionally, the administration of PEA attenuated aggressiveness in a social isolation model of PTSD in mice [25]. Fernandez et al. (2009) [26] revealed that naringin, a bioflavonoid isolated from citrus fruits and an endogenous ligand of $\operatorname{PPAR} \gamma$, had anxiolytic and antidepressant effects. Another study indicated that seipin knockout (Seipin-KO) male mice displayed anxiety- and depression-like behaviour associated with decreased levels of PPAR $\gamma$ mRNA and protein in the hippocampus and cortex [27], and the administration of the PPAR $\gamma$ agonist rosiglitazone attenuated the anxiety-like behaviour in male Seipin-KO mice. PPAR $\gamma$ genetic deletion had anxiogenic effects in mice [10]. In this same investigation, the authors showed that systemic and intra-amygdala injections of pioglitazone (PPAR $\gamma$ agonist) reduced stress-induced anxiety-like behaviour in rats and that these effects were blocked by the administration of the PPAR $\gamma$ antagonist GW9662. Rosiglitazone elicited antidepressant and anxiolytic-like behavioural effects in mice and pretreatment with the PPAR $\gamma$ selective antagonist GW9662 blocked the effects of rosiglitazone [28]. Recently, administration of pioglitazone was shown to attenuate harmaline-induced anxiety-like behaviours and spatial learning and memory impairments [29], similar to what was observed with rosiglitazonetreated animals. Likewise, Youssef et al. (2019) [30] have shown that the administration of GW9662 blocked the anxiolytic effect of beta-caryophyllene. In other work, repeated stress decreased PPAR $\gamma$ expression in the amygdala, and treatment with anxiolytics recovered PPAR $\gamma$ expression [31]. Gemma et al. (2004) [32] demonstrated that young and aged rats fed with a diet rich in rosiglitazone had increased freezing duration in a context-induced fear protocol. In addition, the levels of PEA were shown to be increased in the basolateral amygdala (BLA) of fear-conditioned (FC) rats [33]. Notably, our group has recently shown that the pharmacological blockade of PPAR $\alpha$ and PPAR $\beta / \delta$, in the presence of formalin-evoked nociceptive tone, impaired short-term fear-extinction in rats, while the blockade of PPAR $\gamma$ potentiated conditioned fear responding, suggesting that endogenous signalling through these three PPAR isoforms may reduce expression of conditioned fear in the presence of nociceptive tone [15].

Administration or manipulation of the levels of endogenous ligands at PPARs, some of which are substrates for fatty acid amide hydrolase (FAAH), have also been shown to enhance cognitive performance [34-42]. A few studies indicate a possible modulatory effect of PPARs on memory and learning processes. Mazzola et al. (2009) [12] have shown that the administration of URB597 (a FAAH inhibitor) enhanced the learning of a passive avoidance test, an effect that was attenuated by the administration of a PPAR $\alpha$ antagonist MK886. These authors also demonstrated that the administration of a PPAR $\alpha$ agonist WY14643 produced similar effects to those observed with URB597, and that these effects were also blocked by MK886. Also, a study from Campolongo et al. (2009) [43] indicated that the administration of OEA improved learning of passive avoidance and spatial memory tasks when given immediately post-training, and that the actions of OEA were mimicked by the PPAR $\alpha$ agonist GW7647 and are absent in PPAR $\alpha$ null mice. Recently, Ratano et al. (2017) [44] have shown that the cognitive-enhancing effects of URB597 were dependent on $P P A R \alpha$, as well as $C_{1}$ receptors and $\mathrm{TRPV}_{1}$. Together, these studies indicate a modulatory role of PPAR signalling in memory acquisition and consolidation.

PPARs are also known to modulate pain responses [9]. Previous studies in rodents have shown that the selective activation of PPAR $\alpha$ [20,45-48], PPAR $\beta / \delta[49,50]$, and PPAR $\gamma$ [51-56] has antinociceptive effects. The administration of PEA, an agonist at PPARs, also has antinociceptive effects in rodents [45,48,57-66] and in humans [67,68]. Likewise, administration of the endogenous PPAR ligand OEA, and OEA-derived compounds, diminishes nociceptive behaviour [69-71]. Pain can impact significantly on both anxiety [72-79] and cognition [80]. Moreover, co-morbidity of chronic pain with anxiety disorders and/or cognitive impairment is highly prevalent [81-83]. Recently, our group 
reported that, in the presence of a nociceptive tone, the systemic administration of PPAR $\alpha$ and PPAR $\beta / \delta$ antagonist impaired short-term fear-extinction in rats and the blockade of PPAR $\gamma$ potentiated conditioned fear responding [15].

The aim of the present study was to test the hypothesis that endogenous signalling via PPARs differentially modulates innate anxiety responses and mnemonic function in the presence and absence of inflammatory pain. Selective antagonists were used to block the actions of endogenous ligands at PPARs. Thus, we examined the effects of intraperitoneal administration of GW6471 (PPAR $\alpha$ antagonist), GSK0660 (PPAR $\beta / \delta$ antagonist), GW9662 (PPAR $\gamma$ antagonist), and PEA (agonist at the three isoforms), on rat behaviour in the elevated plus maze (EPM), open field (OF), light-dark box (LDB), and novel object recognition (NOR) tests in the presence or absence of chronic inflammatory pain induced by intra-plantar injection of complete Freund's adjuvant (CFA).

\section{Materials and Methods}

\subsection{Animals}

Experiments were carried out on a total of 80 adult male Sprague-Dawley rats (230-250 g on arrival; Envigo UK, Bicester, UK). The animals were maintained at controlled temperature $\left(22 \pm 2{ }^{\circ} \mathrm{C}\right)$ and humidity $(45-55 \%)$ under standard lighting conditions (12:12 h light-dark cycle, lights on from $07.00 \mathrm{~h}$ ). All experiments were carried out during the light phase. Food and water were available ad libitum. The experimental procedures were approved by the Animal Care and Research Ethics Committee, National University of Ireland, Galway (Project ID: 15-Feb-01, date of approval: 6 May 2015). The work was carried out under license from the Health Products Regulatory Authority in the Republic of Ireland (Project Authorisation: AE19125_P028; Date of Approval: 7 August 2015) and in accordance with EU Directive 2010/63.

The animal studies are reported in compliance with the ARRIVE guidelines for preclinical research described by Percie Du Sertie et al. (2020) [84].

\subsection{Drugs}

GW6471, GSK0660, GW9662 and PEA (all obtained from Tocris Bioscience, Bristol, UK) were dissolved in a 1:1:8 (ethanol:cremophor:saline) vehicle solution. The doses of GW6471 $(2 \mathrm{mg} / \mathrm{kg})$, GSK0660 $(1 \mathrm{mg} / \mathrm{kg})$ and GW9662 $(2 \mathrm{mg} / \mathrm{kg})$ were chosen based on studies in the literature demonstrating the efficacy of these three PPAR antagonists in reversing the antinociceptive and neuroprotective effects of PEA [66,85] or pioglitazone [52,56,86], as well as the results published previously by our group [15]. Immunogenic complete Freund's adjuvant emulsifier (CFA, desiccated Mycobacterium tuberculosis in an 85\% mineral oil, $15 \%$ mannide monooleate suspension, Sigma-Aldrich, Dublin, Ireland) was used to induce a chronic inflammatory pain state [87]. Rats received a single $100 \mu \mathrm{L}$ intraplantar injection of CFA $(1 \mathrm{mg} / \mathrm{mL})$ into the right hind paw, under brief isoflurane anaesthesia $(3 \%$ in $0.8 \mathrm{~L} / \mathrm{min}_{2}$ ). Control rats underwent intraplantar needle insertion to the right hind paw, also under isoflurane anaesthesia.

\subsection{Experimental Design}

The animals were housed initially in groups of three and allowed 4 days of habituation upon arrival. Five days after arrival, seven days before Complete Freud Adjuvant (CFA) injections, the rats were singly housed (the experimental design is summarized in Figure 1). The experimental unit was an individual rat (for behavioural tests) or brain tissue from each individual rat (LC-MS/MS). On day 7 and 10 after arrival (5 and 2 days before CFA injection), the baseline paw withdrawal thresholds for mechanical sensitivity were determined using the von Frey test. The rats were placed in one of the six chambers of the von Frey apparatus where they were allowed to habituate for $15 \mathrm{~min}$. Then, the rats received 9 stimulations in each paw using the von Frey filaments according to the up-and-down method described by Dixon [88]. All responses were recorded and analysed afterwards. On day 12 after arrival, day 7 after single housing, the rats were pseudo-randomly divided 
into two groups such that the average baseline paw withdrawal thresholds did not differ between the two groups: the rats allocated to the CFA-treated group received a $100 \mu \mathrm{L}$ intraplantar injection of CFA into the right hind paw under isoflurane $\left(2-3 \%\right.$ in $\left.\mathrm{O}_{2}, 0.8 \mathrm{~L} / \mathrm{min}\right)$ anaesthesia, while animals in the No-CFA group underwent needle insertion alone into the right hind paw under isoflurane anaesthesia. After injections, the rats were immediately returned to their home cages. On the following day, the first post-CFA paw withdrawal threshold data collection took place, and another set of data was collected on day 7 postCFA injection.

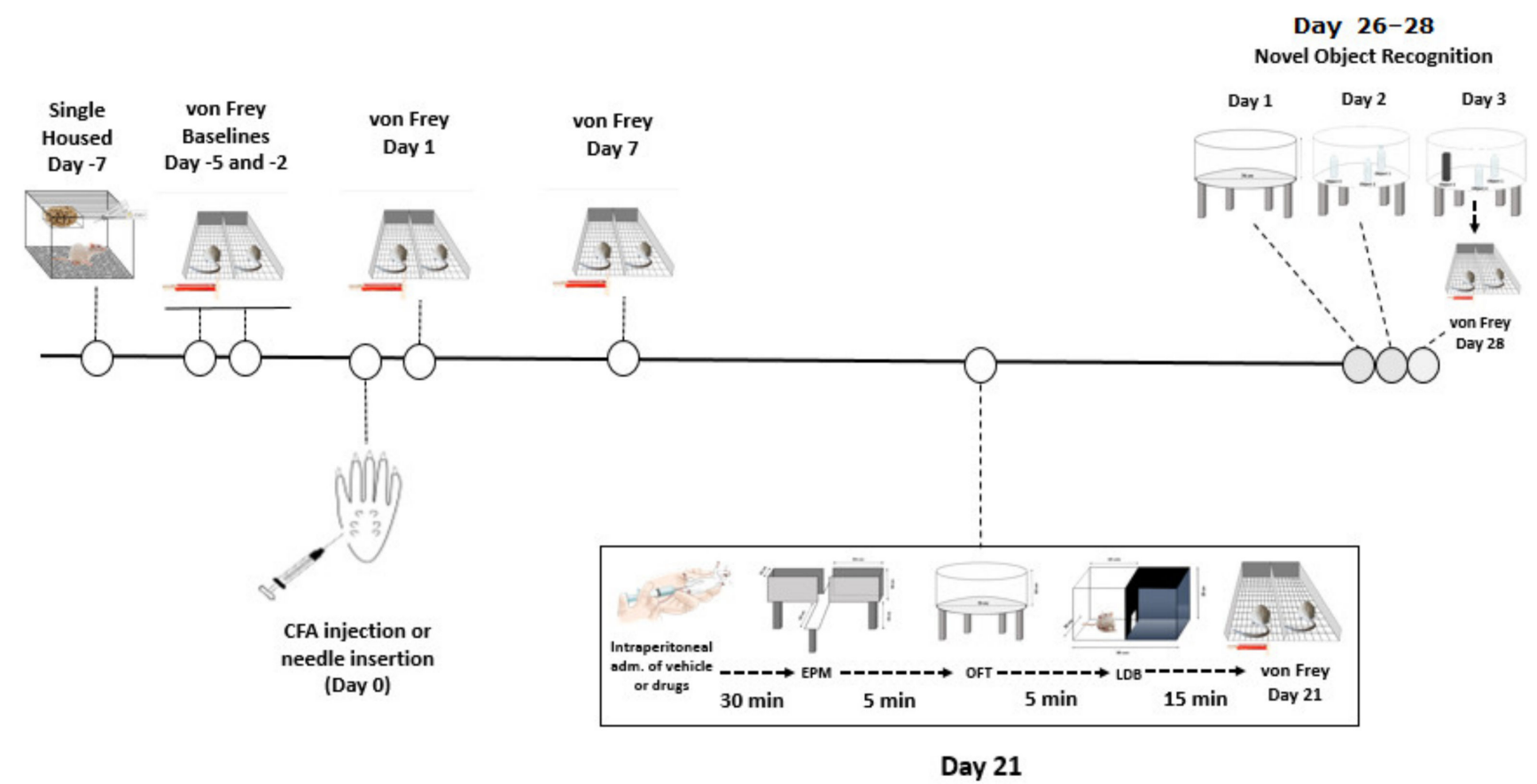

Figure 1. Graphical representation of the experimental design.

On day 21 post-CFA, the rats were tested for anxiety-related behaviour. The animals received an intraperitoneal injection of GW6471 (2 mg/kg), GSK0660 (1 mg/kg), GW9662 $(2 \mathrm{mg} / \mathrm{kg})$, PEA $(2 \mathrm{mg} / \mathrm{kg})$ or vehicle in an injection volume of $3 \mathrm{~mL} / \mathrm{kg}$. Thus, the experimental groups were: Vehicle-No CFA, GW6471-No CFA, GSK0660-No CFA, GW9662No CFA, PEA-No CFA, Vehicle-CFA, GW6471-CFA, GSK0660-CFA, GW9662-CFA, PEACFA. Rats were randomly assigned to treatment groups and the sequence of testing was randomised to avoid confounding effects of test group order. Thirty minutes after injections, the rats underwent a series of anxiety tests: they were initially placed in the elevated plus maze (EPM) arena for $5 \mathrm{~min}$, followed by the open field (OF) test for $5 \mathrm{~min}$, and then the light-dark box (LDB) test also for $5 \mathrm{~min}$. After all the anxiety tests were completed, the rats were again placed in the von Frey apparatus for a $15 \mathrm{~min}$ habituation followed by an assessment of paw withdrawal thresholds. The rats were returned to their home cages after von Frey testing. The time of testing post-injection was chosen based on a previous work published by our research group showing that these antagonists crossed the blood-brain barrier to reach brain tissue and exert pharmacological effects 30 min following intraperitoneal injection [15].

On day 26, post-CFA injection, we initiated the novel object recognition test (NOR) protocol. Briefly, on the first day of the protocol (day 26 post-CFA), rats were allowed to explore the NOR arena, which at this point had no objects, in a habituation trial for $10 \mathrm{~min}$. On the next day (day 27 post-CFA), the rats were exposed to the familiarization phase, in which they were allowed to explore freely for $5 \mathrm{~min}$ in the arena where three plastic bottles filled with water were placed. This protocol was repeated 3 times, with 5-min breaks between exposures. After the third exposure, the rat was returned to its home cage. 
On the test day (day 28 post-CFA), the animals received an intraperitoneal injection of GW6471 (2 mg/kg), GSK0660 (1 mg/kg), GW9662 $(2 \mathrm{mg} / \mathrm{kg})$, PEA $(2 \mathrm{mg} / \mathrm{kg})$ or vehicle in an injection volume of $3 \mathrm{~mL} / \mathrm{kg}$. Rats were pseudo-randomly re-assigned to drug treatment groups relative to the treatments they received prior to anxiety testing on day 21 post-CFA using the Latin Square Randomisation method. Thirty minutes after administration of drugs, the rats were placed in the NOR arena for $5 \mathrm{~min}$, with one of the plastic bottles replaced by a squared plastic structure (novel object). The time spent exploring the familiar water-filled bottles and the novel object was recorded and later analysed. Again, when the NOR test was finished, the rats were placed in the von Frey apparatus for a $15 \mathrm{~min}$ habituation followed by the sixth and final paw withdrawal threshold test. After the von Frey data collection, rats were euthanized by live decapitation and the brains were harvested, snap-frozen on dry ice, and stored at $-80^{\circ} \mathrm{C}$. Sample sizes were based on previous studies with our laboratory and others that followed a similar design and had similar outcome measures. Final sample sizes were $n=8$ per group for the EPM and OF, and $n=7-8$ per group for LDB, von Frey test, NOR and LC-MS/MS. In the LDB, 3 animals failed to move from the initial chamber (light chamber) to the dark chamber (one in each of the following groups: No CFA-Vehicle, No CFA-PEA, CFA-GW6471). In the von Frey test, one animal (in the No-CFA GW6471 group) did not respond to the filaments at baseline and Day 1. In the NOR, 2 rats were deemed outliers for discrimination index and spatial discrimination index ( 1 in No CFA-Vehicle, and 1 in CFA-GW6471), and 6 rats for preference index (1 in each of No CFA-Vehicle, CFA-Vehicle, CFA-GW6471, No CFA-GSK0660, No CFA-PEA, CFA-PEA), based on being $>2 \times$ standard deviations from their group means. For LC-MS/MS, $n=7$ per group for all groups and all analytes except for PEA in the No CFA-Vehicle group where $n=8$.

\subsection{Behavioural Tests}

\subsubsection{Von Frey Test for Mechanical Hypersensitivity}

The von Frey test apparatus comprised a six-chambered arena made of clear Perspex front and back walls and white chipboard lateral walls. The dimensions of the chambers were such that rats could move freely $(14 \mathrm{~cm} \times 20 \mathrm{~cm} \times 25 \mathrm{~cm})$. A Perspex lid with air-holes was placed on top of the arena during the habituation and testing periods. In all experiments, the arena was placed on a raised wire-mesh flooring so that the experimenter (who was blind to treatment) could access the hind paws of the rats from below. Six rats were tested per session, and the arena was thoroughly cleaned between each session using $70 \%$ ethanol. Rats received an initial habituation period of $15 \mathrm{~min}$ during which they were placed in individual chambers of the arena. The baseline withdrawal thresholds were acquired twice, on days -5 and -2 , before CFA intraplantar injection on day 0 . For the statistical analysis, the average of both baselines was used. We applied the up-and-down method described by Dixon [88]. In this method, the rats receive a maximum of 9 nylon von Frey filament stimulations (Touch Test Sensory Evaluator \#58011, Stoelting, IL, USA), starting with the $2 \mathrm{~g}$ filament. Each filament was applied only once, perpendicular to the plantar surface of the hind paw, targeting the area at the base of the third and fourth digits (from medial to lateral) according to the previous protocol used by the group, with sufficient force to cause slight buckling of the filament, for approximately $6 \mathrm{~s}$ or until a positive response was observed. A positive response was recorded if flinching, licking or withdrawal of the paw occurred on application of the filament or immediately after removal of the filament. Filaments were applied to both the left and right hind paws (alternating between paws). First, the thresholds for the contralateral paws of all six rats were collected, followed by the thresholds for the ipsilateral paws. If a positive response was observed using the $2 \mathrm{~g}$ filament, filaments of lower weights (down) were applied in descending order until no positive responses were observed. If there was no response using the $2 \mathrm{~g}$ filament, filaments of higher weights (up) were applied in ascending order until a positive response was observed. In addition, the following approach was followed: positive responses lead to stimulation with the next lowest filament, and negative responses lead to stimulation 
with the next highest filament, until a total of 9 stimuli were applied. These nine digits generate a code that is associated to a constant $(\kappa)$ detailed by Dixon [88]. The final value for the paw withdrawal threshold is calculated using the formula: $10^{\text {[(log (last hair) }+\kappa) * 0.3] \text {. }}$

The withdrawal thresholds of CFA-treated animals were compared to the no-CFA control group and the effect of the treatments on CFA or no-CFA animals compared to the vehicle-treated counterparts (control) was also analysed.

\subsubsection{Elevated Plus Maze}

The EPM arena consisted of a white wooden plus-shaped maze elevated $50 \mathrm{~cm}$ from the room floor with two arms enclosed by walls $(30 \mathrm{~cm})$ and two open arms; the floor was covered in a black rubber material. Each arm was $50 \mathrm{~cm}$ in length and $10 \mathrm{~cm}$ in width and the arms were interconnected by a central platform. A video camera was positioned over the maze and the light levels were fixed at 60 lux in the open arms and 25 lux in the closed arms, according to the protocol previously used by our group. The rat behaviour was recorded and analysed using a computerized video tracking system (EthoVision ${ }^{\circledR}$ XT11.5, Noldus, The Netherlands) for a 5 min period. The EPM was cleaned between animals with $70 \%$ Ethanol. Reduced time spent in the open arm(s) was used as an experimental index of anxiety. Entries in arms were defined as entry of the rat's centre of gravity into the arms (centre point on the body). The time spent in either the open or closed arms by CFA-treated animals was compared to the no-CFA control group and the effect of the treatments on CFA or no-CFA animals compared to the vehicle-treated group (control) was also analysed.

\subsubsection{Open Field Test}

Behaviour in the open field was assessed once according to the experimental design described above in Figure 1. The rats were placed into a brightly lit (200 lux) open field environment (diameter $75 \mathrm{~cm}$ and $40 \mathrm{~cm}$ high walls, of reflective aluminium walls and floor). A camera positioned $35 \mathrm{~cm}$ above the floor of the arena allowed for behaviour to be captured, recorded and assessed using a computerized video tracking system (EthoVision ${ }^{\circledR}$ XT11.5, Noldus, The Netherlands) for a 5 min period. The open field was cleaned between animals with $70 \%$ ethanol. The behavioural assessment included locomotor activity (total distance moved) and time spent (seconds) in the centre zone (45 cm diameter). Reduced time spent in the centre zone is interpreted as anxiety-related behaviour. The time spent in either the centre or periphery of the arena and the total distance moved by CFA-treated animals were compared to the no-CFA control group and the effect of the treatments on CFA or no-CFA animals compared to the vehicle-treated animals (control) was also analysed.

\subsubsection{Light-Dark Box}

Behaviour in the light-dark box was assessed once according to the experimental design described above in Figure 1 . The rats were placed into a $30 \mathrm{~cm} \times 30 \mathrm{~cm} \times 30 \mathrm{~cm}$ Perspex chamber divided into two compartments that were connected by an entrance. One of the compartments is defined as light-chamber and was brightly illuminated (150 lux) while the other was called dark-chamber (0 lux at the corners and 5 lux next to the passage door). A camera was positioned below the arena and the behaviours were recorded and later assessed using a computerized video tracking system (EthoVision ${ }^{\circledR}$ XT11.5, Noldus, The Netherlands) for a 5 min period. The light-dark box arena was cleaned between animals with $70 \%$ ethanol. The behavioural assessment included locomotor activity (total distance moved), time spent (seconds) in each of the chambers and the number of entrances in the dark chamber. Reduced time spent in the light compartment is interpreted as anxietyrelated behaviour. Therefore, the time spent in either the light or dark chamber of the arena, the latency to move from the light to the dark chamber, and the total distance moved by CFA-treated animals were compared to the no-CFA control group, and the effect of the treatments on CFA or no-CFA animals compared to the vehicle-treated animals (control) was also analysed. 


\subsubsection{Novel Object Recognition}

Testing was carried out in the same circular arena used for the open field test. In all experiments, the arena was illuminated by constant light intensity of $100 \pm 10$ lux at floor level of the arena. A camera positioned above recorded the whole test for subsequent analysis. The objects used included $500 \mathrm{~mL}$ unlabelled transparent thin plastic polyethylene terephthalate Coca-Cola ${ }^{\circledR}$ bottles filled with water, and an abstract plastic structure with a base $5 \mathrm{~cm} \times 5 \mathrm{~cm}$ and height $16 \mathrm{~cm}$ constructed from a mixture of green, white and blue toy blocks (Playskool Clipo ${ }^{\circledR}$ blocks; Pawtucket, RI, USA). In all cases, the objects had no apparent natural significance to the rats and were secured to the base of the arena with white tack such that they were difficult to displace. Animals were habituated to the arena in the absence of objects for $10 \mathrm{~min}$ on day 1 (see Figure 2). On the second day (familiarisation), three identical objects (Coca-Cola ${ }^{\circledR}$ bottles; Atlanta, GA, USA) were placed in the arena $16 \mathrm{~cm}$ from points on the perimeter of the circular arena. The rat was allowed to freely explore the arena and objects three times for $5 \mathrm{~min}$, with 5 min intervals between exposures. After this exposure, the animal was removed from the arena and returned to its home cage. On the following day (test), one of the objects was replaced with a novel object (abstract plastic structure constructed with a mixture of green, white and blue toy blocks). The animal was allowed to freely explore the arena and objects for a period of $5 \mathrm{~min}$ and then returned to its home cage. The arena was cleaned with $70 \%$ ethanol and faecal pellets were removed between each exposure to remove odours and olfactory cues. Exploration of an object was defined as sniffing the object, rearing against the object or having the head directed towards the object within $2 \mathrm{~cm}$ of the object. In all cases, the experimenter rating the behaviour was blind to the experimental treatment of the rat (CFA or drug). Ethovision ${ }^{\circledR}$ XT11.5; Wageningen, the Netherlands) as also used to track the distance (in $\mathrm{cm}$ ) moved by the animal during testing. The position of the novel object was alternated between rats in order to minimise potential confounding effects related to orientation biases. Three indices were calculated in order to assess NOR results: (1) the preference index defined as the time spent preferentially with the novel object in relation to the time spent with the familiar object in the same position; (2) the discrimination index defined as the time spent with the novel object in relation to the time spent with the familiar objects in the test day; (3) the spatial discrimination index, defined as the time spent in the location of the new object in relation to the time spent in the same location in the familiarisation phase (the equations used in each of these rations can be seen in Table 1). The time spent exploring the objects and the arena where the objects were located by CFA-treated animals were compared to the no-CFA control group, and the effect of the treatments on CFA or no-CFA animals compared to the vehicle-treated animals (control) was also analysed.

Table 1. Equations for the indices used in the assessment of NOR behaviour.

\begin{tabular}{ccc}
\hline \multicolumn{1}{c}{ Index } & Day & Equation \\
\hline \multirow{2}{*}{ Preference index } & Familiarisation Day & {$\left[\mathrm{T}_{\mathrm{O} 3} /\left(\mathrm{T}_{\mathrm{O} 1}+\mathrm{T}_{\mathrm{O} 2} / 2\right)+\mathrm{T}_{\mathrm{O} 3}\right] \times 100$} \\
\cline { 2 - 3 } & Test Day & {$\left[\mathrm{T}_{\mathrm{N}} /\left(\mathrm{T}_{\mathrm{O} 1}+\mathrm{T}_{\mathrm{O} 2} / 2\right)+\mathrm{T}_{\mathrm{N}}\right] \times 100$} \\
\hline Discrimination index & Test Day & {$\left[\mathrm{T}_{\mathrm{N}} /\left(\mathrm{T}_{\mathrm{O} 1}+\mathrm{T}_{\mathrm{O} 2} / 2\right)+\mathrm{T}_{\mathrm{N}}\right] \times 100$} \\
\hline Spatial Discrimination index & $\begin{array}{c}\text { Familiarisation and } \\
\text { Test Days }\end{array}$ & {$\left[\left(\mathrm{T}_{\mathrm{N}}-\mathrm{T}_{\mathrm{O} 3}\right) /\left(\mathrm{T}_{\mathrm{N}}+\mathrm{T}_{\mathrm{O} 3}\right)\right] \times 100$} \\
\hline $\begin{array}{l}\mathrm{T}_{\mathrm{O} 1}=\text { time exploring Object 1, } \mathrm{T}_{\mathrm{O} 2}=\text { time exploring Object 2, } \mathrm{T}_{\mathrm{O} 3}=\text { time exploring Object 3, and } \mathrm{T}_{\mathrm{N}}=\text { time } \\
\text { exploring the new object. }\end{array}$ &
\end{tabular}




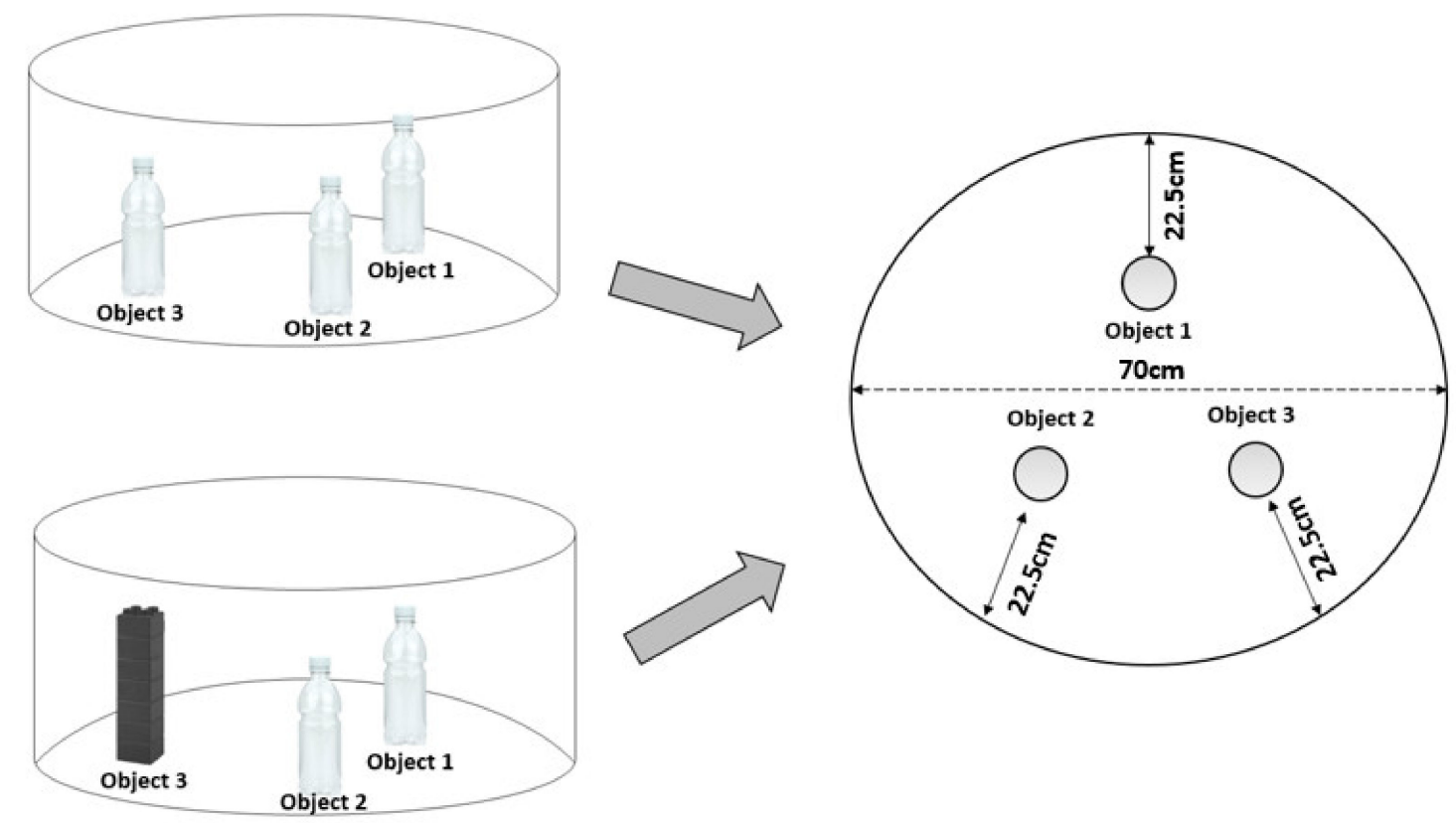

Figure 2. Graphical representation of the NOR arena. The left-top image represents the organisation of the object on the sample (familiarisation) day. The left-bottom image represents the organisation of the objects on the test day (novel object in the position of object 3). The right image shows the equal distances of the object to the wall of the circular arena.

\subsection{Liquid Chromatography_Tandem Mass Spectrometry (LC-MS/MS)}

Tissue extraction was carried out using the following method: the previously dissected brain region samples (dorsal hippocampus and entorhinal cortex) were homogenised for $4-6 \mathrm{~s}$ in a mixture containing $200 \mu \mathrm{L}$ of deuterated internal standards for endocannabinoids $(0.48 \mathrm{nmol} / 50 \mathrm{ng}$ of 2-AG-d8 and $0.014 \mathrm{nmol} / 2.5 \mathrm{ng}$ of AEA-d 8$)$ and NAEs $(0.015 \mathrm{nmol} / 2.5 \mathrm{ng}$ of OEA-d 4 and $0.016 \mathrm{nmol} / 2.5 \mathrm{ng}$ of PEA-d4). The final volume was made up to $275 \mu \mathrm{L}$ by adding $100 \%$ acetonitrile using an ultrasonic homogeniser/sonicator (Mason, Dublin, Ireland). Deuterated and non-deuterated endocannabinoids were purchased from Cayman Chemicals (Cambridge, Biosciences, UK).

Samples were kept on ice during the procedure. The homogenates were centrifuged at 14,000 RPM for 15 min at $4{ }^{\circ} \mathrm{C}$ (Hettich centrifuge Mikro 22R, Tuttlingen, Germany). Immediately after, the supernatant was collected and $40 \mu \mathrm{L}$ was transferred to a HPLC vial. The standard curve was constructed using serial $1 / 4$ dilution by adding $25 \mu \mathrm{L}$ of a mixture of non-deuterated endocannabinoids (12.5 ng for PEA, OEA and AEA + $125 \mathrm{ng}$ for 2-AG) to tube $\# 10$, which contained $75 \mu \mathrm{L}$ of acetonitrile, vortex-mixing, then collecting $25 \mu \mathrm{L}$ and transferring to the next tube (\#9) containing $75 \mu \mathrm{L}$ acetonitrile. The process was repeated until tube \#1, when $25 \mu \mathrm{L}$ of the final volume was discarded, in order to keep the volumes between tubes consistent. Thus, all 10 tubes had $75 \mu \mathrm{L}$ of a mixture of endocannabinoids. All standard curve tubes were spiked with $200 \mu \mathrm{L}$ of deuterated endocannabinoid mixture (2.5 ng deuterated PEA, OEA and AEA and $50 \mathrm{ng}$ deuterated 2-AG as internal standards) to give a final volume of $275 \mu \mathrm{L}$ per tube. $40 \mu \mathrm{L}$ of each standard was transferred to a corresponding HPLC vial. A double blank (100\% acetonitrile) was also included in between each standard point during the run to minimise the risk of analyte carryover from standard to standard at the upper range of the curve and five double blanks were included after the highest concentration point on the curve to avoid carryover onto the samples. A quality control (QC) sample was prepared from the whole rat brain homogenate was included with each run to allow for monitoring of inter-runs variability. The QC was added after all the samples, at the end of the run.

The mobile phase consisted of (A) high-pressure liquid chromatography grade water and (B) acetonitrile, both containing $0.1 \% v / v$ formic acid. At time 0 , solvent ratios were 
$(55: 45)(v / v)$ respectively, remaining as such for $1 \mathrm{~min}$ and then ramped up linearly to $100 \%$ solvent B by minute 5 . The volume of solvent B (100\%) remained as such until minute 12 , whereby the sample run was completed. At $12.1 \mathrm{~min}$, a five-minute equilibration phase occurred between each run to facilitate the return of the gradient to initial conditions specified at time 0 .

Quantitation of each analyte was performed by determining the peak area response of each target analyte against its corresponding deuterated internal standard. This ratiometric analysis was calculated using Masshunter Quantitative Analysis Software B.07.00 (Agilent Technologies Ltd., Cork, Ireland). The amount of analyte in unknown samples was calculated from the analyte/internal standard peak area response ratio using a 10-point calibration curve constructed from a range of concentrations of the non-deuterated form of each analyte and a fixed amount of deuterated internal standard. The values obtained from the Masshunter Quantitative Analysis Software are initially expressed in ng per mg of tissue by dividing the weight of the punched tissue. To express values as nmol or pmols per $\mathrm{mg}$ the corresponding values are then divided by the molar mass of each analyte expressed as $\mathrm{ng} / \mathrm{nmole}$ or $\mathrm{pg} / \mathrm{pmole}$.

\subsection{Statistical Analysis}

The SPSS 24.0 statistical package was used to analyse data. Normality was assessed using Shapiro-Wilk test and homogeneity of variance was checked using Levene's test. Behavioural data were analysed using a two-factor analysis of variance (Two-way ANOVA), with factors being CFA injection and treatment, or repeated measures ANOVA when appropriate (e.g., when the data were analysed and presented in time bins) and the effect size of ANOVA was evaluated by $\eta^{2}$. Post hoc pairwise comparisons were made with Student-Newman-Keuls test when appropriate and effect size was evaluated by Cohen's $\mathrm{d}$ coefficient $(\mathrm{d})$. If data were found to be non-parametric, three transformations were applied, in this order: square root of the data, log of the data, and ranking of the data. In cases where the data, after the transformations, still failed to pass the normality and/or the homogeneity of variance tests, a non-parametric analysis was applied. Non-parametric data were analysed using Kruskal Wallis analysis of variance and post hoc analysis performed using Dunn's test when appropriate. When repeated measures were non-parametric, data were analysed using Friedman's and Kruskal Wallis tests followed by Dunn's post hoc or with Mann Whitney adjusted with Bonferroni-Holm corrections tests if applicable. Data were considered significant when $p<0.05$. Data are expressed as group means \pm standard error of the mean (SEM) when parametric and as median with interquartile range and $\mathrm{min} / \mathrm{max}$ values when non-parametric is unless otherwise stated.

\section{Results}

\subsection{CFA Induced Mechanical Hypersensitivity Measured by von Frey Testing}

Intra-plantar injection of CFA into the right hind paw produced robust nociceptive behaviour as evidenced by the lower ipsilateral hind paw withdrawal thresholds measured in the von Frey testing (baseline $\left[\chi^{2}(9)=8.236, p>0.05\right] \eta^{2}=0.015$; day $1\left[\chi^{2}(9)=35.069\right.$, $p<0.001] \eta^{2}=0.001$; day $7\left[\chi^{2}(9)=48.980, p<0.001\right] \eta^{2}=0.008$; day $21\left[\chi^{2}(9)=51.601\right.$, $p<0.001] \eta^{2}=0.001$; day $\left.28\left[\chi^{2}(9)=39.580, p<0.001\right] \eta^{2}=0.024\right)$. Post hoc Dunn's test indicated significantly lower paw withdrawal thresholds in CFA vehicle-treated animals compared to their No-CFA counterparts in days 1, 7, 21, and 28 (CFA Vehicle vs. No-CFA Vehicle, ${ }^{*} p<0.05$ and ${ }^{* *} p<0.01 ; \mathrm{d}=0.105,0.685,0.813,0.438$; Figure 3$)$. The test also indicated lower paw withdrawal thresholds in CFA GW9662 and PEA-treated animals compared to their No-CFA counterparts (CFA GW9662 vs. No-CFA GW9662, days 7 and $28,{ }^{\#} p<0.05, \mathrm{~d}=-0.285,-0.271$; CFA PEA vs. No-CFA PEA, days 7 and $21,{ }^{\#} p<0.05$, $\mathrm{d}=-0.138,0.068)$. 


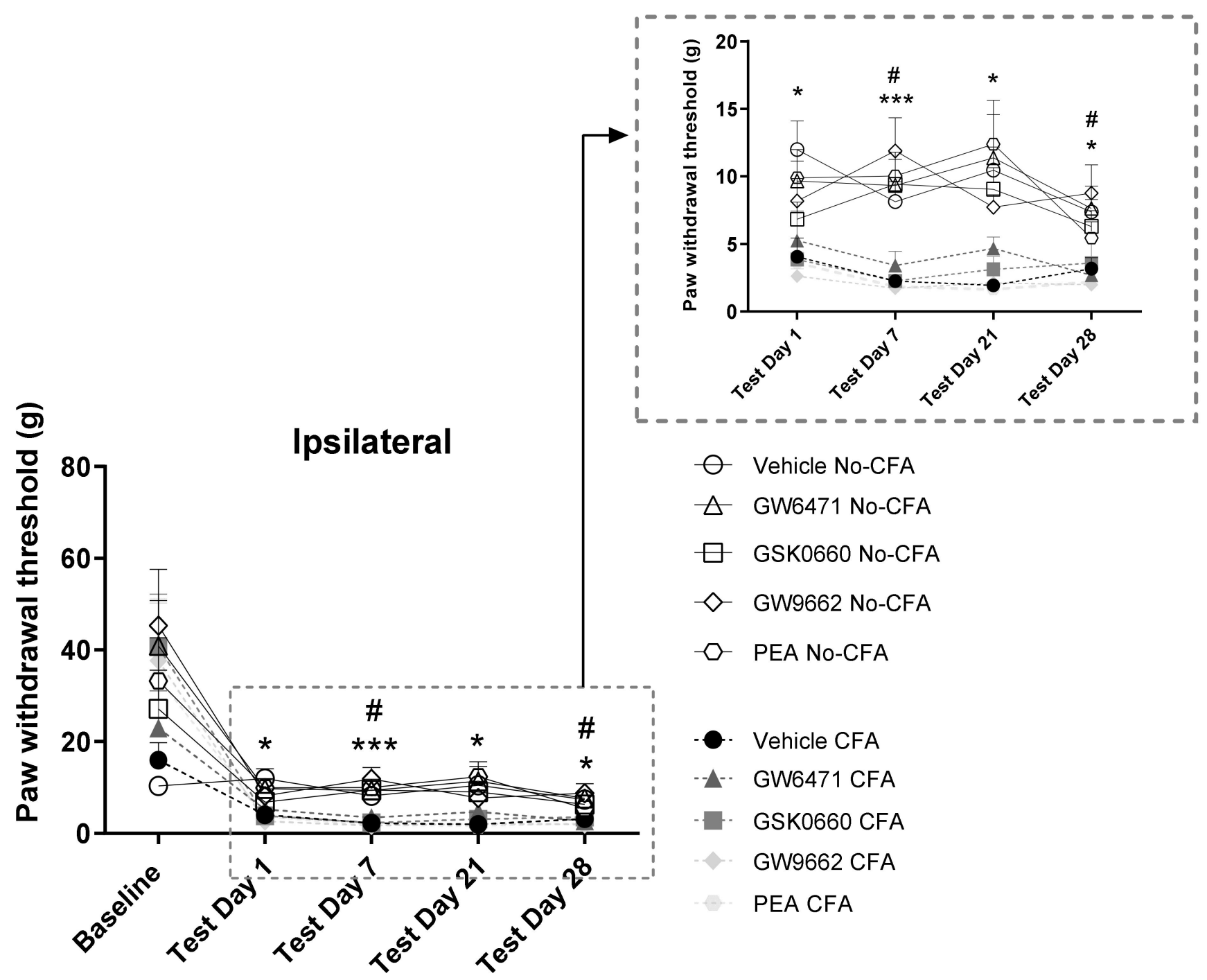

Figure 3. Effects of systemic administration of vehicle, selective PPAR $\alpha$ (GW6471), PPAR $\beta / \delta$ (GSK0660) and PPAR $\gamma$ (GW9662) antagonists, and PEA on mechanical hypersensitivity in CFA-injected (CFA) and control (No-CFA) rats. Post hoc testing indicated significantly lower paw withdrawal thresholds in CFA vehicle-treated animals on days 1, 7, 21, and 28 $\left({ }^{*} p<0.05\right.$ and ${ }^{* * *} p<0.001$, vs. No-CFA Vehicle) in the ipsilateral paw (B). The test also indicated lower paw withdrawal thresholds in CFA GW9662 and PEA-treated animals compared to their No-CFA counterparts (\# $p<0.05$ vs. No- CFA GW9662, days 7 and 28; \# $p<0.05$ vs. No-CFA PEA, days 7 and 21). The von Frey data, which were non-parametric, are presented in timeline graphs as means \pm S.E.M. for presentation/readability purposes ( $n=7-8$ rats per group).

3.2. No Effect of PPAR Antagonists or PEA on Anxiety-Related Behaviour in the Elevated Plus Maze (EPM) in CFA or No-CFA Treated Rats

The systemic administration of PPAR antagonists or PEA did not have any effect on the behaviour of CFA or No-CFA treated animals in the EPM test (Figure 4). Intra-plantar injection of CFA did not affect the behaviour of the animals in the test.

3.3. No Effect of PPAR Antagonists or PEA on Anxiety-Related Behaviour in the Open Field in CFA or No-CFA Treated Rats

The systemic administration of PPAR antagonists or PEA did not have any effect on the behaviour of CFA or No-CFA treated animals in the open field test (Figure 5). Intra-plantar injection of CFA did not affect the behaviour of the animals in the test. 

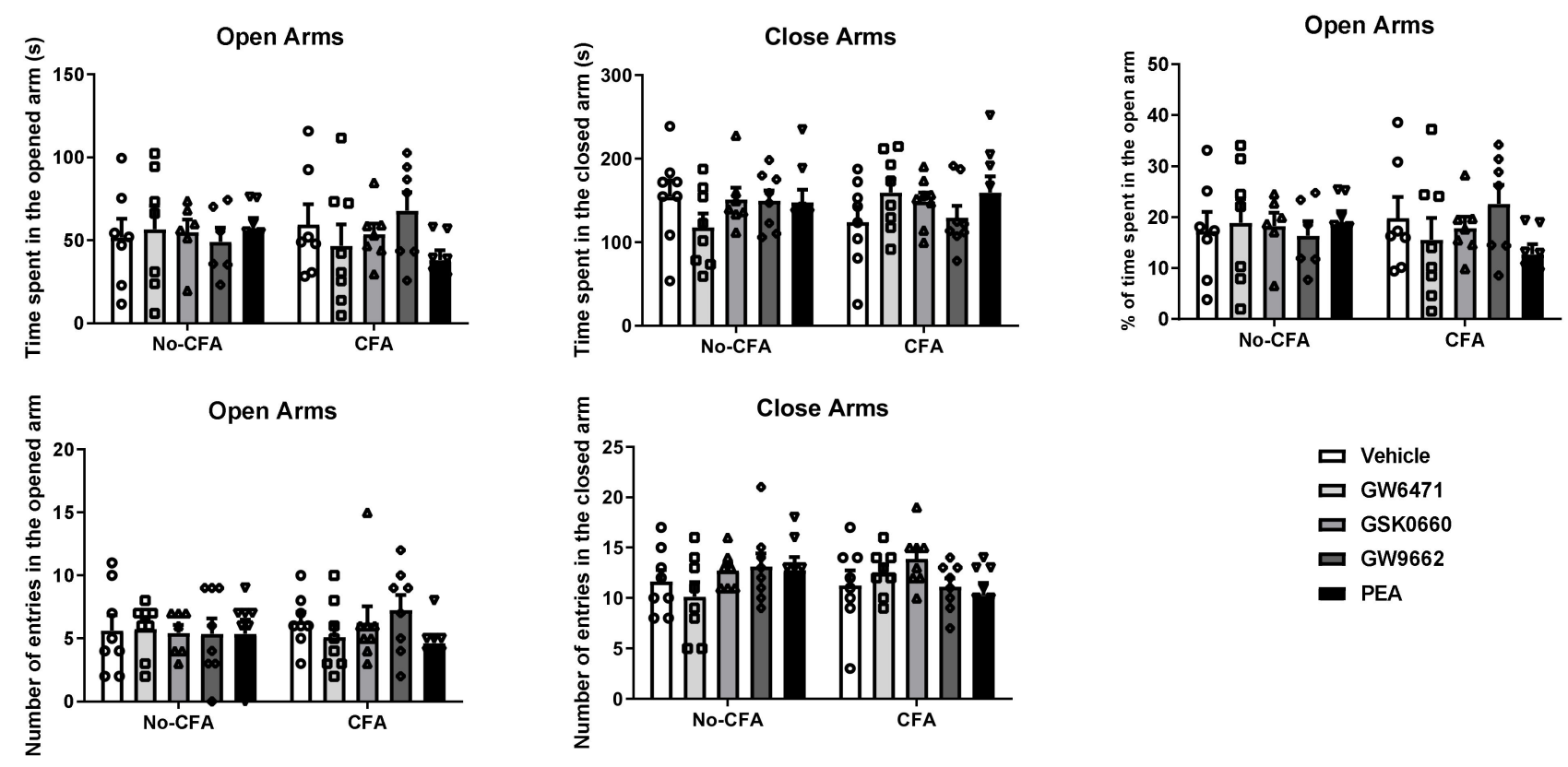

Figure 4. Effects of systemic administration of vehicle, selective PPAR $\alpha$ (GW6471), PPAR $\beta / \delta(G S K 0660)$ and PPAR $\gamma$ (GW9662) antagonists, and PEA on anxiety-related behaviours in the EPM test in CFA-injected (CFA) and control (No-CFA) rats. Data are expressed as means $\pm \operatorname{SEM}$ ( $n=8$ rats per group). The symbols represent each individual data point.
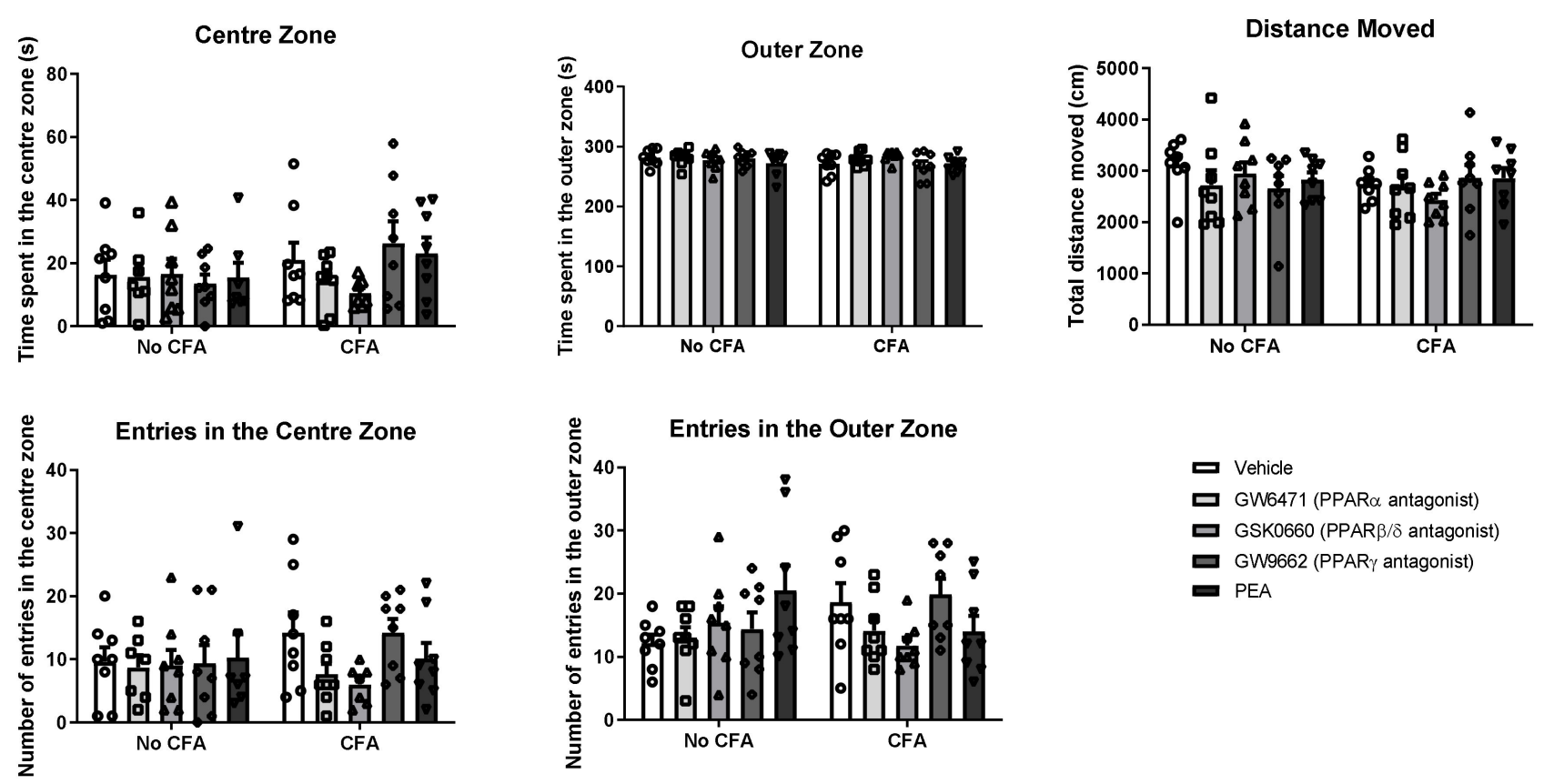

Figure 5. Effects of systemic administration of vehicle, selective PPAR $\alpha$ (GW6471), PPAR $\beta / \delta(G S K 0660)$ and PPAR $\gamma$ (GW9662) antagonists, and PEA on exploratory and anxiety-related behaviours in the OF test in CFA-injected (CFA) and control (No-CFA) rats. Data are expressed as means \pm SEM ( $n=8$ rats per group). The symbols represent each individual data point.

\subsection{Effects of PPAR Antagonists on Anxiety-Related Behaviour in the Light-Dark Box (LDB) in CFA-Treated Rats}

The systemic administration of PPAR antagonists or PEA did not have any significant effect on the behaviour of the animals in the time spent in the dark side $\left(\chi^{2}(9)=5.060\right.$, $p>0.05$; Figure 6A), latency to enter the dark side $\left(\chi^{2}(9)=10.382, p>0.05\right.$; Figure $\left.6 \mathrm{C}\right)$, 
number of entries into the light side $\left(\chi^{2}(9)=11.067, p>0.05\right.$; Figure $\left.6 \mathrm{D}\right)$, or number of entries into the dark side $\left(\chi^{2}(9)=12.610, p>0.05\right.$; Figure $\left.6 \mathrm{E}\right)$ in the light-dark box test. Repeated measures ANOVA revealed a significant effect of time on the time spent in the light side $(\mathrm{F}(4,349)=11.51, p<0.001 ;$ Figure $6 \mathrm{~B})$. An analysis of the area under the curve indicated a trend for a decrease in time spent in the light side in CFA GW6471-treated ( $p=0.075$; Figure $6 \mathrm{~F}$ ) and in CFA GSK0660-treated ( $p=0.07$; Figure $6 \mathrm{G})$ rats compared to CFA vehicle-treated rats.
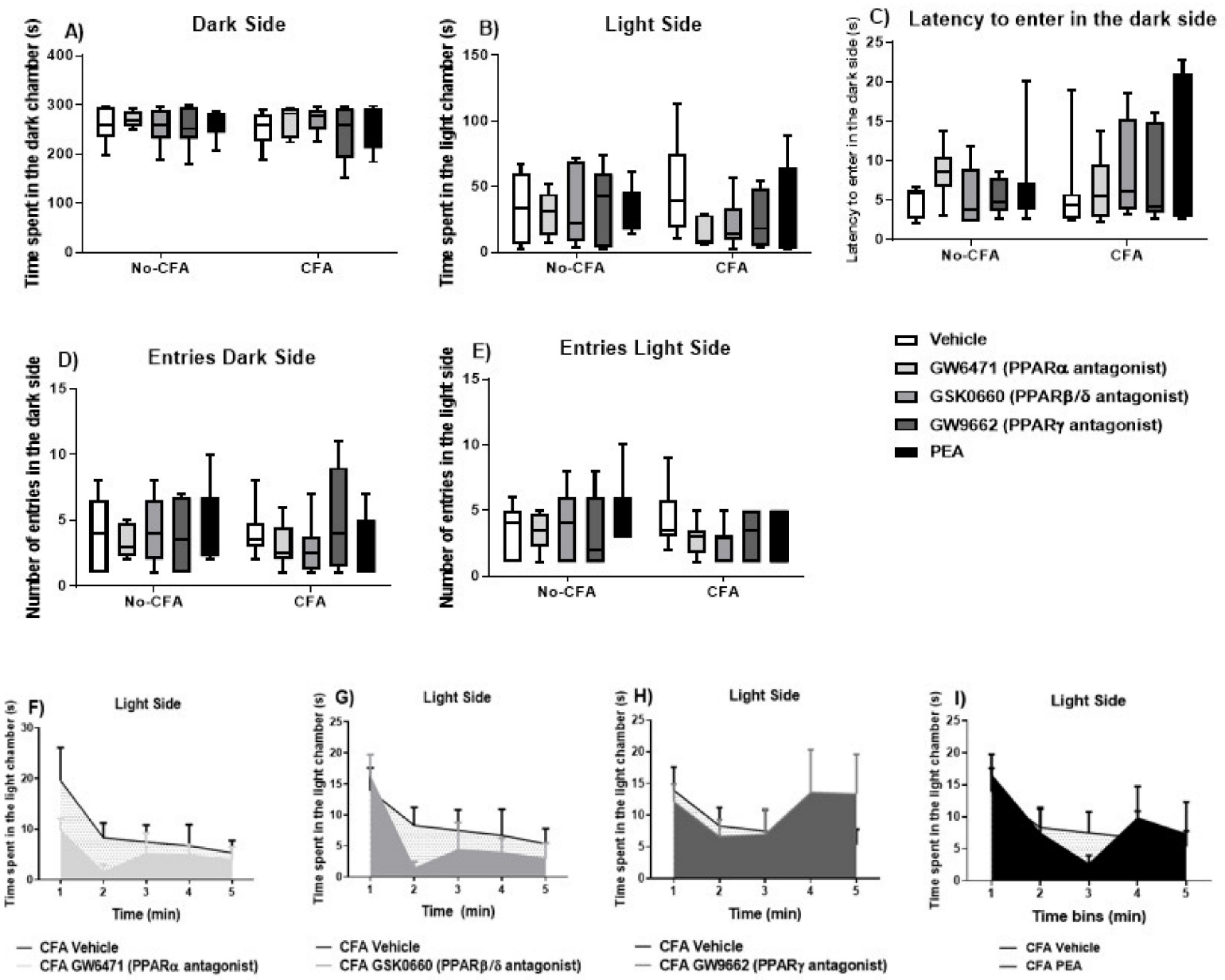

Figure 6. Effects of systemic administration of vehicle, selective PPAR $\alpha$ (GW6471), PPAR $\beta / \delta(G S K 0660)$ and PPAR $\gamma$ (GW9662) antagonists, and PEA on anxiety-related behaviours in the LDB test in CFA-injected (CFA) and control (No-CFA) rats. Data are expressed as median with interquartile range and $\mathrm{min} / \mathrm{max}(\mathbf{A}-\mathbf{E})$ or means $\pm \mathrm{SEM}(\mathrm{F}-\mathbf{I})(n=7-8$ rats per group). In the CFA-injected groups, the area under the curve (AUC) analysis indicated a trend for a decrease in time spent in the light side in GW6471-treated ( $p=0.075 ; \mathrm{F})$ and GSK0660-treated $(p=0.07 ; \mathrm{G})$ rats compared to vehicle counterparts. The AUC analysis was done on all groups together but are presented separately for presentation/readability purposes. Data are presented as means \pm S.E.M. ( $n=7-8$ rats per group).

\subsection{PPAR Antagonist Impairs Spatial Memory Rats in the NOR Test in CFA-Treated Rats}

The results show a significant effect of day $\left[\mathrm{F}(1,140)=50.469,{ }^{\mathrm{a}} p<0.001 ; \eta^{2}=0.248\right]$ on the novel object preference index (percentage of time spent exploring the location of the novel object/object 3; (Figure 7A). However, there were no significant effects of treatment $\left[\mathrm{F}(4,140)=0.772, p>0.05 ; \eta^{2}=0.015\right]$, CFA $\left[\mathrm{F}(1,140)=2.237, p>0.05 ; \eta^{2}=0.011\right]$, or interactions of treatment $x$ CFA $\left[F(4,140)=0.820, p>0.05 ; \eta^{2}=0.016\right]$, treatment $x$ day $\left[\mathrm{F}(4,140)=0.475, p>0.05 ; \eta^{2}=0.009\right], \mathrm{CFA} \times$ day $\left[\mathrm{F}(1,140)=0.553, p>0.05 ; \eta^{2}=0.003\right]$, and treatment $\times$ CFA $\times$ day $\left[\mathrm{F}(4,140)=0.414, p>0.05 ; \eta^{2}=0.008\right]$ on the preference index. Importantly, the analysis also revealed a significant effect of CFA $[F(1,62)=6.006$, 
a $p<0.05 ; \eta^{2}=0.085$ ] on the discrimination index (the percentage of time spent exploring the novel object in relation to the familiar objects in the arena on the test day; Figure 7B). Likewise, there was a significant effect of CFA $\left[F(1,66)=5.105,{ }^{a} p<0.05 ; \eta^{2}=0.048\right]$ on the discrimination index for spatial memory which compares the percentage difference in time exploring the novel object on test day in relation to object 3 placed in the same location on sample day (Figure 7C). When the analysis was carried out in CFA vs. non-CFA animals, separately, there were no significant treatment effects on the discrimination index (despite a trend for the PPAR $\beta$ / $\delta$ antagonist GSK0660 to attenuate the CFA-induced reduction in discrimination index), however a significant treatment effect was revealed in the CFAinjected group for the spatial discrimination index $\left[\mathrm{F}(4,33)=3.239, p<0.05 ; \eta^{2}=0.039\right]$. Post hoc analysis with Student Newman-Keuls test indicated that the PPAR $\alpha$ antagonist GW6471 significantly reduced the discrimination index for spatial memory compared to vehicle-treated CFA rats $\left({ }^{*} p<0.05\right.$, vs. CFA-Vehicle).
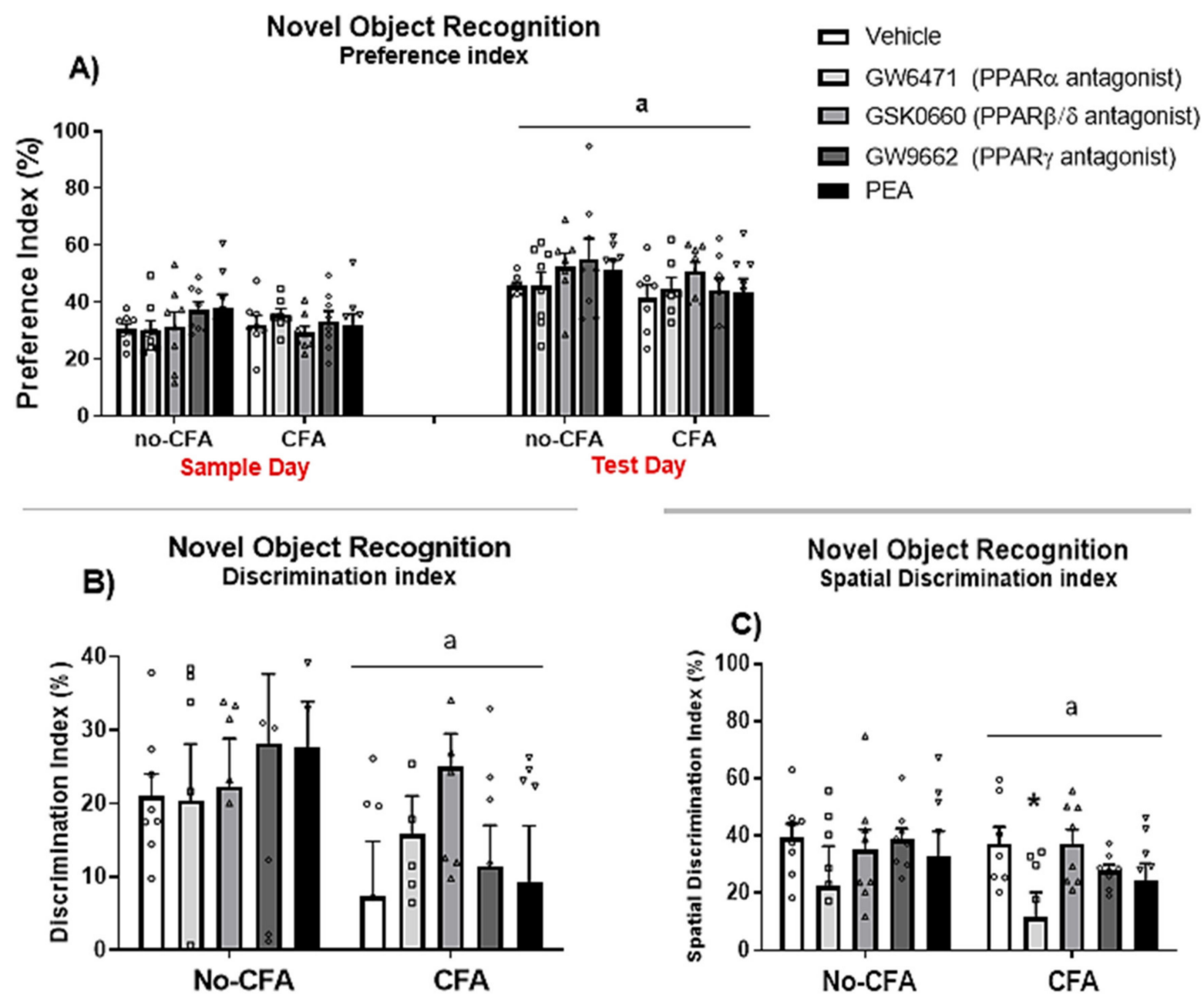

Figure 7. Effects of systemic administration of vehicle, selective PPAR $\alpha$ (GW6471), PPAR $\beta / \delta(G S K 0660)$ and PPAR $\gamma$ (GW9662) antagonists, and PEA on behaviour in the NOR test in CFA-injected (CFA) and control (No-CFA) rats. Two-way ANOVA revealed an effect of day ( $\left.{ }^{\mathrm{a}} p<0.001\right)$ on the percentage of time spent exploring the novel object compared to object 3 (i.e., preference index $=$ TObject 3 or Novel Object $/$ TObject $1+$ TObject $2 / 2)+$ TObject 3 or Novel Object multiplied by 100; (A). CFA injection ( ${ }^{\mathrm{a}} p<0.05 ;(\mathbf{B}, \mathbf{C})$ ) was also shown to have an effect on the discrimination index (Discrimination index $=$ TNovel object $/($ TObject $1+$ TObject $2 / 2)+$ TN multiplied by 100) and on the spatial discrimination index (Spatial discrimination index $=$ TNovel object-TObject3/TNovel object + TObject3 multiplied by 100). GW6471 significantly reduced the spatial discrimination index compared to vehicle-treated CFA rats $\left({ }^{*} p<0.05\right.$, vs. CFA-Vehicle; $\left.(\mathbf{C})\right)$. Data are expressed as means $\pm \operatorname{SEM}(n=7-8$ rats per group). The symbols represent each individual data point. 


\subsection{Increased OEA Levels in the Ipsilateral Dorsal Hippocampus of CFA-Injected Rats}

In order to further explore the reasons underlying the differential effect of PPAR $\alpha$ antagonism on spatial memory depending on the nociceptive tone, the levels of endogenous PPAR ligands (PEA and OEA) in the ipsilateral and contralateral (in relation to the CFA injection which was into the right hind paw) dorsal hippocampus (Figure 8A,B) and entorhinal cortex (Figure 8C,D), two key regions implicated in spatial memory acquisition, were analysed in CFA-vehicle and No-CFA vehicle groups. The results show a significant overall effect of CFA [F $\left.(1,7)=8.987 ; \eta^{2}=0.022\right]$ on the levels of OEA in the dorsal hippocampus (Figure 8B). Post hoc analysis with Student Newman-Keuls test indicated that OEA levels were significantly higher in the ipsilateral dorsal hippocampus of the CFA-vehicle group compared to No-CFA counterparts ( ${ }^{*} p<0.05$, vs. no-CFA; $d=-0.390$ ). Two-way ANOVA pointed to an overall side difference (relative to the CFA injection) on the levels of PEA $\left[F(1,25)=5.109, p=0.0328 ; \eta^{2}=0.022\right]$ in the dorsal hippocampus, but the post hoc analysis with Student Newman-Keuls test did not reveal any further significant differences between relevant groups. CFA injection did result in changes in the levels of OEA or PEA in the entorhinal cortex.

A)

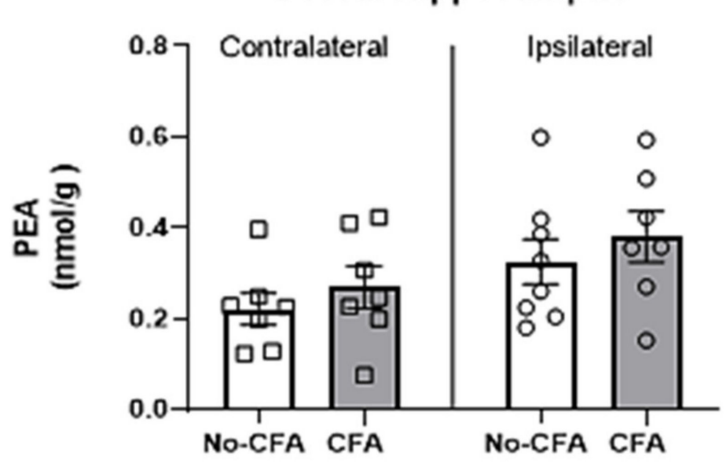

C)
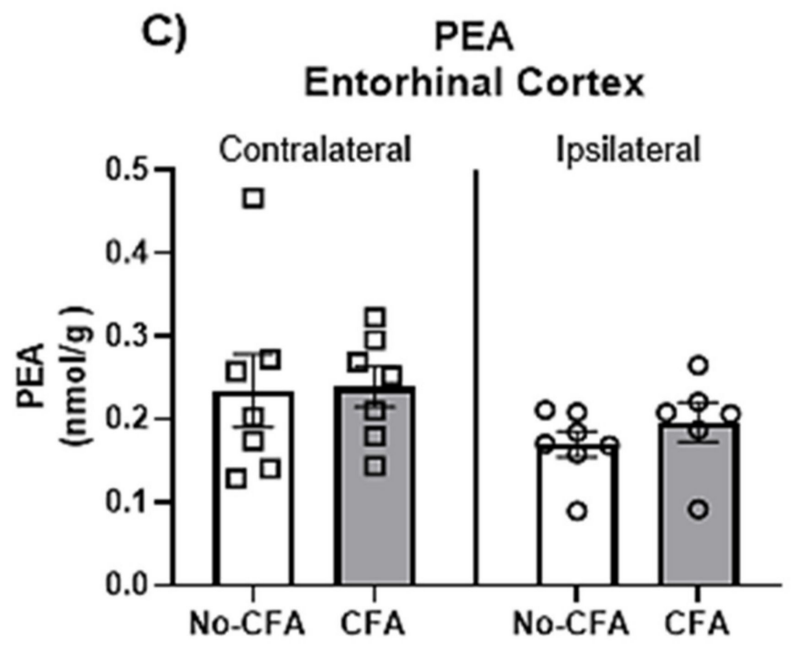

PEA

Dorsal Hippocampus
B)

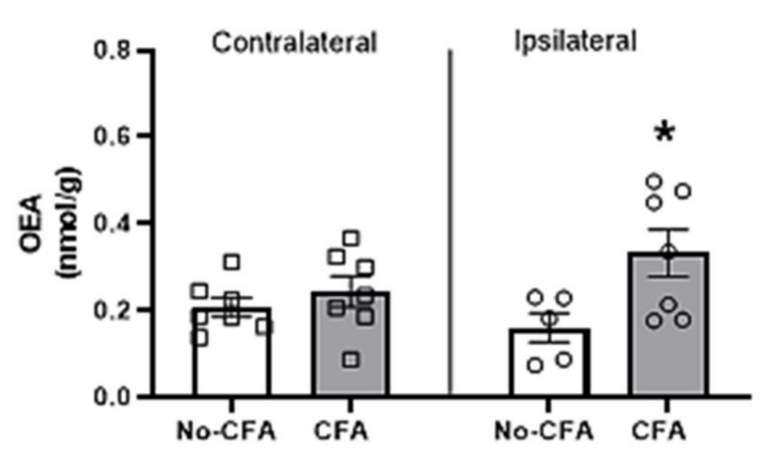

D)
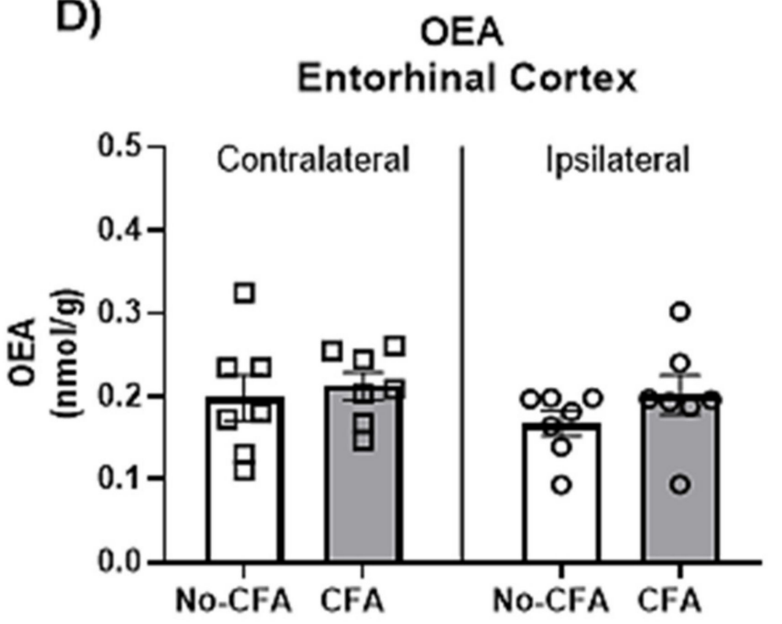

Figure 8. Effects of intraplantar injections of CFA in vehicle-treated animals on the levels of OEA and PEA in the dorsal hippocampus (A,B) and entorhinal cortex (C,D). Two-way ANOVA has shown a significant overall effect of CFA on the levels of OEA in the dorsal hippocampus (B). Post hoc analysis with Student Newman-Keuls test indicated that OEA levels were significantly higher in the ipsilateral dorsal hippocampus of the CFA-vehicle group compared to No-CFA counterparts $\left(\mathbf{B} ;{ }^{*} p<0.05\right.$, vs. no-CFA; $\left.\mathrm{d}=-0.390\right)$. Data are expressed as means $\pm \operatorname{SEM}(n=7-8$ rats per group). 


\section{Discussion}

The study described herein investigated the role of PPARs in innate anxiety responses and mnemonic function in the presence and absence of a nociceptive stimulus. A key finding of the work was that CFA-injected rats exhibited impaired recognition and spatial mnemonic performance in the NOR test and that pharmacological blockade of PPAR $\alpha$ further impaired spatial memory in CFA-treated rats, but had no effect in No-CFA injected controls. The intraplantar administration of CFA resulted in robust mechanical hypersensitivity in the injected paw on days 1, 7, 21 and 28 post-injection. Injection of GW6471, GSK0660, GW9662 or PEA did not alter pain responses at any of these time points. Several studies have demonstrated the involvement of PPAR signalling in pain responses in acute and chronic models of inflammatory pain [9]. Our results do not show any alteration in CFA-induced pain-related behaviour following systemic administration of PPAR antagonists. These findings are in accordance with Donvito et al. (2017) [89], Mansouri et al. (2015) and our previous results [15], demonstrating that intraperitoneal administration of GW6471 and GW9662 did not affect nociceptive behaviour in the formalin test of tonic, persistent inflammatory pain. Other studies have shown antinociceptive effects of PEA-induced PPAR activation in rodent models of inflammatory $[48,59,90]$ and neuropathic $[48,57,63,64,66,71,91]$ pain, including a study using CFA injections in the temporomandibular nerve [92]. Therefore, our results for PEA diverge to some extent from those reported in the literature, which may relate to differences in our experimental design and methodology compared to other studies.

In the current study, CFA injections did not affect anxiety-related behaviour in the EPM, OF or LDB tests. This result is at odds with other studies showing CFA-induced anxiety. For instance, Parent et al. (2012) [92] have shown that intraplantar injection of CFA induced anxiogenic behaviours in the EPM and OF, but not LDB, tests in rats. Although the authors used the same tests and the same rat strain used herein, they chose different time points post-CFA to run their tests (i.e., day 28-30 vs. day 21 in the present study). Hofmann et al. (2017) [93] have seen CFA-induced anxiety-like behaviour in the LDB and EPM tests with mice $48 \mathrm{~h}$ after CFA injection. Other studies have also shown increased anxiety-like behaviours in mice in EPM and OF tests 7 days [94,95], 21 days [96,97], and 6 weeks [98] post-CFA injection. Similarly, intraplantar injections of CFA also resulted in increased anxiety-related behaviour in mice in the place escape/avoidance paradigm (PEAP) and elevated zero maze tests [99]. The injection of CFA into the temporomandibular joint also produced anxiety-like behaviours in the EPM and LDB tests in Wistar rats [100]. In summary, these studies indicate an anxiogenic effect induced by CFA injections. However, differences in the animal model (i.e., rats vs. mice, Sprague-Dawley vs. Wistar) and the time points at which the tests were performed could explain the discrepant results seen in the present study. Several studies have indicated that PPAR signalling is involved in the regulation of anxiety responses. However, in the present study, the systemic administration of PPAR antagonists or PEA did not markedly affect the behaviour of rats in the EPM, OF and LDB tests, although a trend for an anxiogenic effect of the blockade of PPAR $\alpha$ and PPAR $\beta / \delta$ in the CFA-injected animals was observed in the LDB test. The findings described here are in accordance with Panlilio et al. (2009) [100] who reported that the systemic administration of MK886, a PPAR $\alpha$ antagonist, did not alter anxiety-like behaviour in the OF test. The lack of significant effect of PPAR antagonism on anxiety-like behaviour is not in line with what was observed by Domi et al. (2016), who demonstrated that the administration of GW9662 had anxiogenic effects in mice in the LDB, OF, and EPM tests. However, the use of different species may explain the difference in results. To our knowledge, the present study is the first one to investigate the effects of the blockade of PPAR $\beta / \delta$ in anxiety responses. Both pioglitazone and rosiglitazone (PPAR $\gamma$ agonists) have previously been shown to elicit anxiolytic-like effects in the LDB, EPM, and OF tests $[28,29,101]$. Only one recent study has investigated the effect of PEA on anxietyrelated behaviour and showed that chronic administration of PEA increased exploration time in the OF test, an effect blocked by the PPAR $\alpha$ antagonist MK886 [43]. However, these 
authors used a higher concentration of PEA (i.e., $2.5 \mathrm{mg} / \mathrm{kg}$ ) than that used in the present study and only analysed exploratory behaviour and immobility in the OF test.

Furthermore, in the present experiment, CFA-injected rats exhibited impaired recognition and spatial mnemonic performance in the NOR test. These results are in accordance with previous studies that have indicated CFA-induced cognitive deficits. Yang et al. (2014) [102] have demonstrated that CFA injection impairs the learning of tone-footshock, but not context-footshock, association in mice. Interestingly, we found that the administration of the PPAR $\alpha$ antagonist GW6471 further impaired spatial memory in CFA-injected rats, but not in No-CFA injected controls. Importantly, the analysis of the levels of endogenous ligands at PPARs in the dorsal hippocampus conducted in the present study has shown that OEA levels were higher in CFA-injected animals compared to No-CFA counterparts. This difference in OEA levels related to inflammatory pain status may explain the differential effect of PPAR $\alpha$ antagonism at the behavioural level. A previous study revealed that a 5-day treatment with OEA restored ethanol/THC-related decreases in both short-term spatial memory (spontaneous alternation by Y-maze) and circulating levels of BDNF in the dorsal hippocampus [84], revealing an important role for OEA in memory formation. Interpreting our results in the context of these findings, it is possible that increased OEA levels in the hippocampus may act at PPAR $\alpha$ as a compensatory mechanism to preserve the reduced level of spatial memory function that remains following CFA injection. This may explain why pharmacological blockade of PPAR $\alpha$ impaired spatial memory in CFA-injected rats but not in No-CFA controls. The effects of PPAR blockade on cognitive tasks is less explored. In the present study, the systemic administration of GW6471 reduced spatial mnemonic performance in the NOR test in CFA-treated rats. Additionally, the administration of PEA did not have any effect on cognitive performance. An effect of PPAR activation on learning has previously been described. Mazzola et al. (2009) [12] showed that the administration of URB597 (FAAH inhibitor) before the learning trial of a passive avoidance test enhanced the learning of the task, and this enhancement was attenuated by the administration of a PPAR $\alpha$ antagonist MK886. These authors also demonstrated that the administration of a PPAR $\alpha$ agonist WY14643 produced learning enhancement effects similar to those observed with URB597, which were also blocked by MK886. Also, a study from Campolongo et al. (2009) [43] indicated that the administration of OEA improved learning of passive avoidance and spatial memory tasks when given immediately post-training and that the actions of OEA were mimicked by the PPAR $\alpha$ agonist GW7647 while being absent in PPAR $\alpha$ null mice. Recently, Ratano et al. (2017) [44] have shown that the cognitive-enhancing effects of URB597 are dependent on PPAR $\alpha$, as well as on CB1 and TRPV1 receptors. Pioglitazone administration improved short-term mnemonic performance in mice, an effect most likely mediated through the PPAR $\gamma$ pathway [103]. However, the data herein did not observe any effect of PPAR $\gamma$ antagonism on object recognition memory. Furthermore, the data demonstrate a lack of effect of PEA in the NOR task, although the specific effect of PEA on cognition still needs to be explored in greater detail.

In conclusion, these results provide evidence for a modulatory effect of CFA-induced chronic inflammatory pain on cognitive processing, but not on innate anxiety-related responses. Moreover, while PPAR $\beta / \delta$ and PPAR $\gamma$ blockade or PEA did not modulate pain, cognition- or anxiety-related behaviour, blockade of PPAR $\alpha$ exacerbated the CFA-induced impairment of spatial memory and tended to increase anxiety-related responses in the LDB test without affecting mechanical hypersensitivity. Increased OEA-PPAR $\alpha$ signalling may act as a compensatory mechanism to preserve spatial memory function following CFA injection.

Author Contributions: Conceptualization, J.C.G., M.R. and D.P.F.; Data curation, J.C.G., C.H., M.I.F. and D.P.F.; Formal analysis, J.C.G.; Funding acquisition, J.C.G. and D.P.F.; Investigation, J.C.G., and C.H.; Methodology, J.C.G.; Project administration, D.P.F; Resources, J.C.G. and D.P.F.; Supervision, M.R. and D.P.F.; Writing—original draft, J.C.G.; Writing—review \& editing, C.H., M.I.F., M.R. and D.P.F. All authors have read and agreed to the published version of the manuscript. 
Funding: This research was funded by Conselho Nacional de Pesquisa (CNPq)—Brazil (\#207530/20149). JCG was funded by a PhD scholarship from Conselho Nacional de Pesquisa (CNPq) —Brazil.

Institutional Review Board Statement: The experimental procedures were approved by the Animal Care and Research Ethics Committee, National University of Ireland Galway. The work was carried out under license from the Health Products Regulatory Authority in the Republic of Ireland and in accordance with EU Directive 2010/63.

Informed Consent Statement: Not applicable.

Data Availability Statement: The data presented in this study are available on request from the corresponding author.

Conflicts of Interest: The authors declare no conflict of interest. The funders had no role in the design of the study; in the collection, analyses, or interpretation of data; in the writing of the manuscript, or in the decision to publish the results.

\section{References}

1. Issemann, I.; Green, S. Activation of a member of the steroid hormone receptor superfamily by peroxisome proliferators. Nature 1990, 347, 645-650. [CrossRef]

2. Marion-Letellier, R.; Savoye, G.; Ghosh, S. Fatty acids, eicosanoids and PPAR gamma. Eur. J. Pharmacol. 2016, 785, 44-49. [CrossRef] [PubMed]

3. Bouaboula, M.; Hilairet, S.; Marchand, J.; Fajas, L.; Le Fur, G.; Casellas, P. Anandamide induced PPAR $\gamma$ transcriptional activation and 3T3-L1 preadipocyte differentiation. Eur. J. Pharmacol. 2005, 517, 174-181. [CrossRef] [PubMed]

4. Rockwell, C.E.; Snider, N.T.; Thompson, J.T.; Heuvel, J.P.V.; Kaminski, N.E. Interleukin-2 Suppression by 2-Arachidonyl Glycerol Is Mediated through Peroxisome Proliferator-Activated Receptor $\gamma$ Independently of Cannabinoid Receptors 1 and 2. Mol. Pharmacol. 2006, 70, 101-111. [CrossRef]

5. LoVerme, J.; La Rana, G.; Russo, R.; Calignano, A.; Piomelli, D. The search for the palmitoylethanolamide receptor. Life Sci. 2005, 77, 1685-1698. [CrossRef] [PubMed]

6. Fu, J.; Gaetani, S.; Oveisi, F.; Lo Verme, J.; Serrano, A.; Rodríguez de Fonseca, F.; Rosengarth, A.; Luecke, H.; Di Giacomo, B.; Tarzia, G.; et al. Oleylethanolamide regulates feeding and body weight through activation of the nuclear receptor PPAR- $\alpha$. Nature 2003, 425, 90-93. [CrossRef] [PubMed]

7. Hong, F.; Xu, P.; Zhai, Y. The Opportunities and Challenges of Peroxisome Proliferator-Activated Receptors Ligands in Clinical Drug Discovery and Development. Int. J. Mol. Sci. 2018, 19, 2189. [CrossRef]

8. Fruchart, J.C.; Staels, B.; Duriez, P. The role of fibric acids in atherosclerosis. Curr. Atheroscler. Rep. 2001, 3, 83-92. [CrossRef]

9. Okine, B.N.; Gaspar, J.C.; Finn, D.P. PPARs and pain. Br. J. Pharmacol. 2018. [CrossRef]

10. Domi, E.; Uhrig, S.; Soverchia, L.; Spanagel, R.; Hansson, A.C.; Barbier, E.; Heilig, M.; Ciccocioppo, R.; Ubaldi, M. Genetic Deletion of Neuronal PPAR $\gamma$ Enhances the Emotional Response to Acute Stress and Exacerbates Anxiety: An Effect Reversed by Rescue of Amygdala PPAR $\gamma$ Function. J. Neurosci. 2016, 36, 12611-12623. [CrossRef]

11. Varvel, S.A.; Wise, L.E.; Niyuhire, F.; Cravatt, B.F.; Lichtman, A.H. Inhibition of Fatty-Acid Amide Hydrolase Accelerates Acquisition and Extinction Rates in a Spatial Memory Task. Neuropsychopharmacology 2007, 32, 1032-1041. [CrossRef]

12. Mazzola, C.; Medalie, J.; Scherma, M.; Panlilio, L.V.; Solinas, M.; Tanda, G.; Drago, F.; Cadet, J.L.; Goldberg, S.R.; Yasar, S. Fatty acid amide hydrolase (FAAH) inhibition enhances memory acquisition through activation of PPAR-alpha nuclear receptors. Learn. Mem. 2009, 16, 332-337. [CrossRef]

13. Babaei, R.; Javadi-Paydar, M.; Sharifian, M.; Mahdavian, S.; Almasi-Nasrabadi, M.; Norouzi, A.; Dehpour, A.R. Involvement of nitric oxide in pioglitazone memory improvement in morphine-induced memory impaired mice. Pharmacol. Biochem. Behav. 2012, 103, 313-321. [CrossRef] [PubMed]

14. d'Angelo, M.; Castelli, V.; Catanesi, M.; Antonosante, A.; Dominguez-Benot, R.; Ippoliti, R.; Benedetti, E.; Cimini, A. PPAR $\gamma$ and Cognitive Performance. Int. J. Mol. Sci. 2019, 20, 5068. [CrossRef]

15. Gaspar, J.C.; Okine, B.N.; Llorente-Berzal, A.; Roche, M.; Finn, D.P. Pharmacological blockade of PPAR isoforms increases conditioned fear responding in the presence of nociceptive tone. Molecules 2020, 25, 1007. [CrossRef]

16. Duan, S.Z.; Usher, M.G.; Mortensen, R.M. PPARs: The vasculature, inflammation and hypertension. Curr. Opin. Nephrol. Hypertens. 2009, 18, 128-133. [CrossRef] [PubMed]

17. Bensinger, S.J.; Tontonoz, P. Integration of metabolism and inflammation by lipid-activated nuclear receptors. Nature 2008, 454, 470-477. [CrossRef]

18. Warden, A.; Truitt, J.; Merriman, M.; Ponomareva, O.; Jameson, K.; Ferguson, L.B.; Mayfield, R.D.; Harris, R.A.; Berger, J.; Moller, D.E.; et al. Localization of PPAR isotypes in the adult mouse and human brain. Sci. Rep. 2016, 6, 27618. [CrossRef] [PubMed]

19. Moreno, S.; Farioli-Vecchioli, S.; Cerù, M. Immunolocalization of peroxisome proliferator-activated receptors and retinoid $x$ receptors in the adult rat CNS. Neuroscience 2004, 123, 131-145. [CrossRef] [PubMed]

20. Okine, B.N.; Rea, K.; Olango, W.M.; Price, J.; Herdman, S.; Madasu, M.K.; Roche, M.; Finn, D.P. A role for PPAR $\alpha$ in the medial prefrontal cortex in formalin-evoked nociceptive responding in rats. Br. J. Pharmacol. 2014, 171, 1462-1471. [CrossRef] 
21. Okine, B.N.; Gaspar, J.C.; Madasu, M.K.; Olango, W.M.; Harhen, B.; Roche, M.; Finn, D.P. Characterisation of peroxisome proliferator-activated receptor signalling in the midbrain periaqueductal grey of rats genetically prone to heightened stress, negative affect and hyperalgesia. Brain Res. 2017, 1657, 185-192. [CrossRef]

22. Hillard, C.J. Circulating Endocannabinoids: From Whence Do They Come and Where are They Going? Neuropsychopharmacology 2018, 43, 155-172. [CrossRef] [PubMed]

23. Bluett, R.J.; Gamble-George, J.C.; Hermanson, D.J.; Hartley, N.D.; Marnett, L.J.; Patel, S. Central anandamide deficiency predicts stress-induced anxiety: Behavioral reversal through endocannabinoid augmentation. Transl. Psychiatry 2014, 4, e408. [CrossRef] [PubMed]

24. Wilker, S.; Pfeiffer, A.; Elbert, T.; Ovuga, E.; Karabatsiakis, A.; Krumbholz, A.; Thieme, D.; Schelling, G.; Kolassa, I.-T. Endocannabinoid concentrations in hair are associated with PTSD symptom severity. Psychoneuroendocrinology 2016, 67, 198-206. [CrossRef] [PubMed]

25. Locci, A.; Geoffroy, P.; Miesch, M.; Mensah-Nyagan, A.-G.; Pinna, G. Social Isolation in Early versus Late Adolescent Mice Is Associated with Persistent Behavioral Deficits That Can Be Improved by Neurosteroid-Based Treatment. Front. Cell. Neurosci. 2017, 11, 208. [CrossRef]

26. Fernandez, S.P.; Nguyen, M.; Yow, T.T.; Chu, C.; Johnston, G.A.R.; Hanrahan, J.R.; Chebib, M. The Flavonoid Glycosides, Myricitrin, Gossypin and Naringin Exert Anxiolytic Action in Mice. Neurochem. Res. 2009, 34, 1867-1875. [CrossRef] [PubMed]

27. Zhou, L.; Yin, J.; Wang, C.; Liao, J.; Liu, G.; Chen, L. Lack of seipin in neurons results in anxiety- and depression-like behaviors via down regulation of PPAR $\gamma$. Hum. Mol. Genet. 2014, 23, 4094-4102. [CrossRef]

28. Guo, M.; Li, C.; Lei, Y.; Xu, S.; Zhao, D.; Lu, X.-Y. Role of the adipose PPAR $\gamma$-adiponectin axis in susceptibility to stress and depression/anxiety-related behaviors. Mol. Psychiatry 2017, 22, 1056-1068. [CrossRef]

29. Aghaei, I.; Hajali, V.; Haghani, M.; Vaziri, Z.; Moosazadeh, M.; Shabani, M. Peroxisome proliferator-activated receptor- $\gamma$ activation attenuates harmaline-induced cognitive impairments in rats. J. Clin. Neurosci. 2019, 59, 276-283. [CrossRef]

30. Youssef, D.A.; El-Fayoumi, H.M.; Mahmoud, M.F. Beta-caryophyllene alleviates diet-induced neurobehavioral changes in rats: The role of CB2 and PPAR- $\gamma$ receptors. Biomed. Pharmacother. 2019, 110, 145-154. [CrossRef]

31. Liu, H.-Y.; Yue, J.; Hu, L.-N.; Cheng, L.-F.; Wang, X.-S.; Wang, X.-J.; Feng, B. Chronic minocycline treatment reduces the anxietylike behaviors induced by repeated restraint stress through modulating neuroinflammation. Brain Res. Bull. 2018, 143, 19-26. [CrossRef] [PubMed]

32. Gemma, C.; Stellwagen, H.; Fister, M.; Coultrap, S.J.; Mesches, M.H.; Browning, M.D.; Bickford, P.C. Rosiglitazone improves contextual fear conditioning in aged rats. Neuroreport 2004, 15, 2255-2259. [CrossRef]

33. Rea, K.; Olango, W.M.; Harhen, B.; Kerr, D.M.; Galligan, R.; Fitzgerald, S.; Moore, M.; Roche, M.; Finn, D.P. Evidence for a role of GABAergic and glutamatergic signalling in the basolateral amygdala in endocannabinoid-mediated fear-conditioned analgesia in rats. Pain 2013, 154, 576-585. [CrossRef]

34. Zimmermann, T.; Bartsch, J.C.; Beer, A.; Lomazzo, E.; Guggenhuber, S.; Lange, M.D.; Bindila, L.; Pape, H.-C.; Lutz, B. Impaired anandamide/palmitoylethanolamide signaling in hippocampal glutamatergic neurons alters synaptic plasticity, learning, and emotional responses. Neuropsychopharmacology 2019, 44, 1377-1388. [CrossRef]

35. Boccella, S.; Cristiano, C.; Romano, R.; Iannotta, M.; Belardo, C.; Farina, A.; Guida, F.; Piscitelli, F.; Palazzo, E.; Mazzitelli, M.; et al. Ultra-micronized palmitoylethanolamide rescues the cognitive decline-associated loss of neural plasticity in the neuropathic mouse entorhinal cortex-dentate gyrus pathway. Neurobiol. Dis. 2019, 121, 106-119. [CrossRef]

36. Scuderi, C.; Bronzuoli, M.R.; Facchinetti, R.; Pace, L.; Ferraro, L.; Broad, K.D.; Serviddio, G.; Bellanti, F.; Palombelli, G.; Carpinelli, G.; et al. Ultramicronized palmitoylethanolamide rescues learning and memory impairments in a triple transgenic mouse model of Alzheimer's disease by exerting anti-inflammatory and neuroprotective effects. Transl. Psychiatry 2018, 8, 32. [CrossRef]

37. Kramar, C.; Loureiro, M.; Renard, J.; Laviolette, S.R. Palmitoylethanolamide Modulates GPR55 Receptor Signaling in the Ventral Hippocampus to Regulate Mesolimbic Dopamine Activity, Social Interaction, and Memory Processing. Cannabis Cannabinoid Res. 2017, 2, 8-20. [CrossRef]

38. Campolongo, P.; Roozendaal, B.; Trezza, V.; Cuomo, V.; Astarita, G.; Fu, J.; McGaugh, J.L.; Piomelli, D. Fat-induced satiety factor oleoylethanolamide enhances memory consolidation. Proc. Natl. Acad. Sci. USA 2009, 106, 8027-8031. [CrossRef] [PubMed]

39. Rueda-Orozco, P.E.; Montes-Rodriguez, C.J.; Ruiz-Contreras, A.E.; Mendez-Diaz, M.; Prospero-Garcia, O. The effects of anandamide and oleamide on cognition depend on diurnal variations. Brain Res. 2017, 1672, 129-136. [CrossRef] [PubMed]

40. Segev, A.; Korem, N.; Mizrachi Zer-Aviv, T.; Abush, H.; Lange, R.; Sauber, G.; Hillard, C.J.; Akirav, I. Role of endocannabinoids in the hippocampus and amygdala in emotional memory and plasticity. Neuropsychopharmacology 2018, 43, 2017-2027. [CrossRef] [PubMed]

41. Morena, M.; Roozendaal, B.; Trezza, V.; Ratano, P.; Peloso, A.; Hauer, D.; Atsak, P.; Trabace, L.; Cuomo, V.; McGaugh, J.L.; et al. Endogenous cannabinoid release within prefrontal-limbic pathways affects memory consolidation of emotional training. Proc. Natl. Acad. Sci. USA 2014, 111, 18333-18338. [CrossRef]

42. Goonawardena, A.V.; Sesay, J.; Sexton, C.A.; Riedel, G.; Hampson, R.E. Pharmacological elevation of anandamide impairs short-term memory by altering the neurophysiology in the hippocampus. Neuropharmacology 2011, 61, 1016-1025. [CrossRef]

43. Campolongo, P.; Roozendaal, B.; Trezza, V.; Hauer, D.; Schelling, G.; McGaugh, J.L.; Cuomo, V. Endocannabinoids in the rat basolateral amygdala enhance memory consolidation and enable glucocorticoid modulation of memory. Proc. Natl. Acad. Sci. USA 2009, 106, 4888-4893. [CrossRef] 
44. Ratano, P.; Palmery, M.; Trezza, V.; Campolongo, P. Cannabinoid Modulation of Memory Consolidation in Rats: Beyond the Role of Cannabinoid Receptor Subtype 1. Front. Pharmacol. 2017, 8, 200. [CrossRef] [PubMed]

45. D'Agostino, G.; La Rana, G.; Russo, R.; Sasso, O.; Iacono, A.; Esposito, E.; Mattace Raso, G.; Cuzzocrea, S.; LoVerme, J.; Piomelli, D.; et al. Central administration of palmitoylethanolamide reduces hyperalgesia in mice via inhibition of NF- $\mathrm{kB}$ nuclear signalling in dorsal root ganglia. Eur. J. Pharmacol. 2009, 613, 54-59. [CrossRef]

46. Russo, R.; LoVerme, J.; La Rana, G.; D'Agostino, G.; Sasso, O.; Calignano, A.; Piomelli, D. Synergistic antinociception by the cannabinoid receptor agonist anandamide and the PPAR- $\alpha$ receptor agonist GW7647. Eur. J. Pharmacol. 2007, 566, 117-119. [CrossRef] [PubMed]

47. Sagar, D.R.; Kendall, D.A.; Chapman, V. Inhibition of fatty acid amide hydrolase produces PPAR-alpha-mediated analgesia in a rat model of inflammatory pain. Br. J. Pharmacol. 2008, 155, 1297-1306. [CrossRef]

48. LoVerme, J.; Russo, R.; La Rana, G.; Fu, J.; Farthing, J.; Mattace-Raso, G.; Meli, R.; Hohmann, A.; Calignano, A.; Piomelli, D. Rapid broad-spectrum analgesia through activation of peroxisome proliferator-activated receptor-alpha. J. Pharmacol. Exp. Ther. 2006, 319, 1051-1061. [CrossRef]

49. Gill, N.; Bijjem, K.R.V.; Sharma, P.L. Anti-inflammatory and anti-hyperalgesic effect of all-trans retinoic acid in carrageenaninduced paw edema in Wistar rats: Involvement of peroxisome proliferator-activated receptor- $\beta / \delta$ receptors. Indian J. Pharmacol. 2013, 45, 278-282. [CrossRef]

50. Lyons, D.N.; Zhang, L.; Pandya, J.D.; Danaher, R.J.; Ma, F.; Miller, C.S.; Sullivan, P.G.; Sirbu, C.; Westlund, K.N. Combination Drug Therapy of Pioglitazone and D-cycloserine Attenuates Chronic Orofacial Neuropathic Pain and Anxiety by Improving Mitochondrial Function Following Trigeminal Nerve Injury. Clin. J. Pain 2018, 34, 168. [CrossRef] [PubMed]

51. Morgenweck, J.; Abdel-aleem, O.S.; McNamara, K.C.; Donahue, R.R.; Badr, M.Z.; Taylor, B.K. Activation of peroxisome proliferator-activated receptor $\gamma$ in brain inhibits inflammatory pain, dorsal horn expression of Fos, and local edema. Neuropharmacology 2010, 58, 337-345. [CrossRef]

52. Mansouri, M.T.; Naghizadeh, B.; Ghorbanzadeh, B.; Rajabi, H.; Pashmforoush, M. Pharmacological evidence for systemic and peripheral antinociceptive activities of pioglitazone in the rat formalin test: Role of PPAR $\gamma$ and nitric oxide. Eur. J. Pharmacol. 2017. [CrossRef] [PubMed]

53. Oliveira, A.C.P.; Bertollo, C.M.; Rocha, L.T.S.; Nascimento, E.B.; Costa, K.A.; Coelho, M.M. Antinociceptive and antiedematogenic activities of fenofibrate, an agonist of PPAR alpha, and pioglitazone, an agonist of PPAR gamma. Eur. J. Pharmacol. 2007, 561, 194-201. [CrossRef]

54. Hasegawa-Moriyama, M.; Ohnou, T.; Godai, K.; Kurimoto, T.; Nakama, M.; Kanmura, Y. Peroxisome proliferator-activated receptor-gamma agonist rosiglitazone attenuates postincisional pain by regulating macrophage polarization. Biochem. Biophys. Res. Commun. 2012, 426, 76-82. [CrossRef]

55. Churi, S.B.; Abdel-Aleem, O.S.; Tumber, K.K.; Scuderi-Porter, H.; Taylor, B.K. Intrathecal rosiglitazone acts at peroxisome proliferator-activated receptor-gamma to rapidly inhibit neuropathic pain in rats. J. Pain 2008, 9, 639-649. [CrossRef] [PubMed]

56. Griggs, R.B.; Donahue, R.R.; Morgenweck, J.; Grace, P.M.; Sutton, A.; Watkins, L.R.; Taylor, B.K. Pioglitazone rapidly reduces neuropathic pain through astrocyte and nongenomic PPAR $\gamma$ mechanisms. Pain 2015, 156, 469-482. [CrossRef]

57. Di Cesare Mannelli, L.; Pacini, A.; Corti, F.; Boccella, S.; Luongo, L.; Esposito, E.; Cuzzocrea, S.; Maione, S.; Calignano, A.; Ghelardini, C. Antineuropathic Profile of N-Palmitoylethanolamine in a Rat Model of Oxaliplatin-Induced Neurotoxicity. PLoS ONE 2015, 10, e0128080. [CrossRef]

58. Okine, B.N.; Madasu, M.K.; McGowan, F.; Prenderg3ast, C.; Gaspar, J.C.; Harhen, B.; Roche, M.; Finn, D.P. N-palmitoylethanolamide in the anterior cingulate cortex attenuates inflammatory pain behaviour indirectly via a CB1 receptor-mediated mechanism. Pain 2016, 157, 2687-2696. [CrossRef]

59. Sasso, O.; Russo, R.; Vitiello, S.; Raso, G.M.; D’Agostino, G.; Iacono, A.; La Rana, G.; Vallée, M.; Cuzzocrea, S.; Piazza, P.V.; et al. Implication of allopregnanolone in the antinociceptive effect of N-palmitoylethanolamide in acute or persistent pain. Pain 2012, 153, 33-41. [CrossRef]

60. Wang, J.; Zhang, Q.; Zhao, L.; Li, D.; Fu, Z.; Liang, L. Down-regulation of PPAR $\alpha$ in the spinal cord contributes to augmented peripheral inflammation and inflammatory hyperalgesia in diet-induced obese rats. Neuroscience 2014, 278, 165-178. [CrossRef]

61. De Novellis, V.; Luongo, L.; Guida, F.; Cristino, L.; Palazzo, E.; Russo, R.; Marabese, I.; D’ Agostino, G.; Calignano, A.; Rossi, F.; et al. Effects of intra-ventrolateral periaqueductal grey palmitoylethanolamide on thermoceptive threshold and rostral ventromedial medulla cell activity. Eur. J. Pharmacol. 2012, 676, 41-50. [CrossRef]

62. D’Agostino, G.; La Rana, G.; Russo, R.; Sasso, O.; Iacono, A.; Esposito, E.; Raso, G.M.; Cuzzocrea, S.; Lo Verme, J.; Piomelli, D.; et al. Acute Intracerebroventricular Administration of Palmitoylethanolamide, an Endogenous Peroxisome Proliferator-Activated Receptor- Agonist, Modulates Carrageenan-Induced Paw Edema in Mice. J. Pharmacol. Exp. Ther. 2007, 322, 1137-1143. [CrossRef] [PubMed]

63. Costa, B.; Comelli, F.; Bettoni, I.; Colleoni, M.; Giagnoni, G. The endogenous fatty acid amide, palmitoylethanolamide, has anti-allodynic and anti-hyperalgesic effects in a murine model of neuropathic pain: Involvement of CB1, TRPV1 and PPAR $\gamma$ receptors and neurotrophic factors. Pain 2008, 139, 541-550. [CrossRef] [PubMed]

64. Bettoni, I.; Comelli, F.; Colombo, A.; Bonfanti, P.; Costa, B. Non-neuronal cell modulation relieves neuropathic pain: Efficacy of the endogenous lipid palmitoylethanolamide. CNS Neurol. Disord. Drug Targets 2013, 12, 34-44. [CrossRef] 
65. Donvito, G.; Bettoni, I.; Comelli, F.; Colombo, A.; Costa, B. Palmitoylethanolamide relieves pain and preserves pancreatic islet cells in a murine model of diabetes. CNS Neurol. Disord. Drug Targets 2015, 14, 452-462. [CrossRef] [PubMed]

66. Donvito, G.; Wilkerson, J.L.; Damaj, M.I.; Lichtman, A.H. Palmitoylethanolamide Reverses Paclitaxel-Induced Allodynia in Mice. J. Pharmacol. Exp. Ther. 2016, 359, 310-318. [CrossRef]

67. Gabrielsson, L.; Mattsson, S.; Fowler, C.J. Palmitoylethanolamide for the treatment of pain: Pharmacokinetics, safety and efficacy. Br. J. Clin. Pharmacol. 2016, 82, 932-942. [CrossRef]

68. Hesselink, J.M.K.; Hekker, T.A. Therapeutic utility of palmitoylethanolamide in the treatment of neuropathic pain associated with various pathological conditions: A case series. J. Pain Res. 2012, 437. [CrossRef]

69. Vasconcelos, M.A.L.; Royo, V.A.; Ferreira, D.S.; Crotti, A.E.M.; de Silva, M.L.A.; Carvalho, J.C.T.; Bastos, J.K.; Cunha, W.R. In vivo Analgesic and Anti-Inflammatory Activities of Ursolic Acid and Oleanoic Acid from Miconia albicans (Melastomataceae). Zeitschrift für Naturforsch. C 2006, 61. [CrossRef] [PubMed]

70. Suardíaz, M.; Estivill-Torrús, G.; Goicoechea, C.; Bilbao, A.; Rodríguez de Fonseca, F. Analgesic properties of oleoylethanolamide (OEA) in visceral and inflammatory pain. Pain 2007, 133, 99-110. [CrossRef]

71. Guida, F.; Luongo, L.; Marmo, F.; Romano, R.; Iannotta, M.; Napolitano, F.; Belardo, C.; Marabese, I.; D'Aniello, A.; De Gregorio, D.; et al. Palmitoylethanolamide reduces pain-related behaviors and restores glutamatergic synapses homeostasis in the medial prefrontal cortex of neuropathic mice. Mol. Brain 2015, 8, 47. [CrossRef] [PubMed]

72. Zhang, M.; Liu, J.; Zhou, M.-M.; Wu, H.; Hou, Y.; Li, Y.-F.; Yin, Y.; Zheng, L.; Cai, J.; Liao, F.-F.; et al. Anxiolytic effects of hippocampal neurosteroids in normal and neuropathic rats with spared nerve injury. J. Neurochem. 2017, 141, 137-150. [CrossRef]

73. Kontinen, V.K.; Kauppila, T.; Paananen, S.; Pertovaara, A.; Kalso, E. Behavioural measures of depression and anxiety in rats with spinal nerve ligation-induced neuropathy. Pain 1999, 80, 341-346. [CrossRef]

74. Demyttenaere, K.; Bruffaerts, R.; Lee, S.; Posada-Villa, J.; Kovess, V.; Angermeyer, M.C.; Levinson, D.; de Girolamo, G.; Nakane, H.; Mneimneh, Z.; et al. Mental disorders among persons with chronic back or neck pain: Results from the world mental health surveys. Pain 2007, 129, 332-342. [CrossRef] [PubMed]

75. Jiang, H.; Fang, D.; Kong, L.Y.; Jin, Z.R.; Cai, J.; Kang, X.J.; Wan, Y.; Xing, G.G. Sensitization of neurons in the central nucleus of the amygdala via the decreased GABAergic inhibition contributes to the development of neuropathic pain-related anxiety-like behaviors in rats. Mol. Brain 2014, 7, 72. [CrossRef] [PubMed]

76. Fonseca-Rodrigues, D.; Amorim, D.; Almeida, A.; Pinto-Ribeiro, F. Emotional and cognitive impairments in the peripheral nerve chronic constriction injury model (CCI) of neuropathic pain: A systematic review. Behav. Brain Res. 2021, 399, 113008. [CrossRef]

77. Humo, M.; Lu, H.; Yalcin, I. The molecular neurobiology of chronic pain-induced depression. Cell Tissue Res. 2019, 377, 21-43. [CrossRef]

78. Guida, F.; De Gregorio, D.; Palazzo, E.; Ricciardi, F.; Boccella, S.; Belardo, C.; Iannotta, M.; Infantino, R.; Formato, F.; Marabese, I.; et al. Behavioral, Biochemical and Electrophysiological Changes in Spared Nerve Injury Model of Neuropathic Pain. Int. J. Mol. Sci. 2020, 21, 3396. [CrossRef]

79. Karoly, P. How Pain Shapes Depression and Anxiety: A Hybrid Self-regulatory/Predictive Mind Perspective. J. Clin. Psychol. Med. Settings 2020, 1-11. [CrossRef] [PubMed]

80. Moriarty, O.; McGuire, B.E.; Finn, D.P. The effect of pain on cognitive function: A review of clinical and preclinical research. Prog. Neurobiol. 2011, 93, 385-404. [CrossRef]

81. De Heer, E.W.; Gerrits, M.M.J.G.; Beekman, A.T.F.; Dekker, J.; van Marwijk, H.W.J.; de Waal, M.W.M.; Spinhoven, P.; Penninx, B.W.J.H.; van der Feltz-Cornelis, C.M. The Association of Depression and Anxiety with Pain: A Study from NESDA. PLoS ONE 2014, 9, e106907. [CrossRef]

82. De Heer, E.W.; ten Have, M.; van Marwijk, H.W.J.; Dekker, J.; de Graaf, R.; Beekman, A.T.F.; van der Feltz-Cornelis, C.M. Pain as a risk factor for common mental disorders. Results from the Netherlands Mental Health Survey and Incidence Study-2. Pain 2018, 159, 712-718. [CrossRef] [PubMed]

83. Gerrits, M.M.J.G.; van Marwijk, H.W.J.; van Oppen, P.; van der Horst, H.; Penninx, B.W.J.H. Longitudinal association between pain, and depression and anxiety over four years. J. Psychosom. Res. 2015, 78, 64-70. [CrossRef]

84. Percie Du Sertid, N.; Hurst, V.; Ahluwaliaid, A.; Alamid, S.; Aveyid, M.T.; Baker, M.; Browneid, W.J.; Clarkid, A.; Cuthillid, I.C.; Dirnaglid, U.; et al. The ARRIVE guidelines 2.0: Updated guidelines for reporting animal research. J. Cereb. Blood Flow Metab. 2020, 40, 1769-1777. [CrossRef]

85. Paterniti, I.; Impellizzeri, D.; Crupi, R.; Morabito, R.; Campolo, M.; Esposito, E.; Cuzzocrea, S. Molecular evidence for the involvement of PPAR-delta and PPAR-gamma in anti-inflammatory and neuroprotective activities of palmitoylethanolamide after spinal cord trauma. J. Neuroinflamm. 2013, 10, 20. [CrossRef]

86. Morgenweck, J.; Griggs, R.B.; Donahue, R.R.; Zadina, J.E.; Taylor, B.K. PPAR $\gamma$ activation blocks development and reduces established neuropathic pain in rats. Neuropharmacology 2013, 70, 236-246. [CrossRef] [PubMed]

87. Stein, C.; Millan, M.J.; Herz, A. Unilateral inflammation of the hindpaw in rats as a model of prolonged noxious stimulation: Alterations in behavior and nociceptive thresholds. Pharmacol. Biochem. Behav. 1988, 31, 445-451. [CrossRef]

88. Dixon, W.J. The Up-and-Down Method for Small Samples. J. Am. Stat. Assoc. 1965, 60, 967-978. [CrossRef]

89. Donvito, G.; Bagdas, D.; Toma, W.; Rahimpour, E.; Jackson, A.; Meade, J.A.; AlSharari, S.; Kulkarni, A.R.; Ivy Carroll, F.; Lichtman, A.H.; et al. The interaction between alpha 7 nicotinic acetylcholine receptor and nuclear peroxisome proliferator-activated receptor- $\alpha$ represents a new antinociceptive signaling pathway in mice. Exp. Neurol. 2017, 295, 194-201. [CrossRef] [PubMed] 
90. Di Cesare Mannelli, L.; D'Agostino, G.; Pacini, A.; Russo, R.; Zanardelli, M.; Ghelardini, C.; Calignano, A. Palmitoylethanolamide Is a Disease-Modifying Agent in Peripheral Neuropathy: Pain Relief and Neuroprotection Share a PPAR-Alpha-Mediated Mechanism. Mediators Inflamm. 2013, 2013, 1-12. [CrossRef]

91. Bartolucci, M.L.; Marini, I.; Bortolotti, F.; Impellizzeri, D.; Di Paola, R.; Bruschetta, G.; Crupi, R.; Portelli, M.; Militi, A.; Oteri, G.; et al. Micronized palmitoylethanolamide reduces joint pain and glial cell activation. Inflamm. Res. 2018, 67, 891-901. [CrossRef] [PubMed]

92. Parent, A.J.; Beaudet, N.; Beaudry, H.; Bergeron, J.; Bérubé, P.; Drolet, G.; Sarret, P.; Gendron, L. Increased anxiety-like behaviors in rats experiencing chronic inflammatory pain. Behav. Brain Res. 2012, 229, 160-167. [CrossRef]

93. Hofmann, L.; Karl, F.; Sommer, C.; Üçeyler, N. Affective and cognitive behavior in the alpha-galactosidase a deficient mouse model of Fabry disease. PLoS ONE 2017, 12, e0180601. [CrossRef]

94. Yue, J.; Wang, X.; Guo, Y.; Zheng, K.; Liu, H.; Hu, L.; Zhao, M.; Liu, S. Anxiolytic effect of CPEB1 knockdown on the amygdala of a mouse model of inflammatory pain. Brain Res. Bull. 2018, 137, 156-165. [CrossRef]

95. Guo, H.; Xiao, Y.; Tian, Z.; Li, X.; Wang, D.; Wang, X.; Zhang, Z.; Zhao, M.; Liu, S. Anxiolytic effects of sesamin in mice with chronic inflammatory pain. Nutr. Neurosci. 2016, 19, 231-236. [CrossRef]

96. Wang, D.-S.; Tian, Z.; Guo, Y.-Y.; Guo, H.-L.; Kang, W.-B.; Li, S.; Den, Y.-T.; Li, X.-B.; Feng, B.; Feng, D.; et al. Anxiolytic-like effects of translocator protein (TSPO) ligand ZBD-2 in an animal model of chronic pain. Mol. Pain 2015, 11, 16. [CrossRef] [PubMed]

97. Shi, M.; Wang, J.-Y.; Luo, F. Depression Shows Divergent Effects on Evoked and Spontaneous Pain Behaviors in Rats. J. Pain 2010, 11, 219-229. [CrossRef]

98. Refsgaard, L.K.; Hoffmann-Petersen, J.; Sahlholt, M.; Pickering, D.S.; Andreasen, J.T. Modelling affective pain in mice: Effects of inflammatory hypersensitivity on place escape/avoidance behaviour, anxiety and hedonic state. J. Neurosci. Methods 2016, 262, 85-92. [CrossRef]

99. do Nascimento, G.C.; Leite-Panissi, C.R.A. Time-dependent analysis of nociception and anxiety-like behavior in rats submitted to persistent inflammation of the temporomandibular joint. Physiol. Behav. 2014, 125, 1-7. [CrossRef]

100. Panlilio, L.V.; Mazzola, C.; Medalie, J.; Hahn, B.; Justinova, Z.; Drago, F.; Cadet, J.L.; Yasar, S.; Goldberg, S.R.; Goldberg, S.R. Anandamide-induced behavioral disruption through a vanilloid-dependent mechanism in rats. Psychopharmacology 2009, 203, 529-538. [CrossRef]

101. Silva-Peña, D.; Rivera, P.; Alén, F.; Vargas, A.; Rubio, L.; García-Marchena, N.; Pavón, F.J.; Serrano, A.; Rodríguez de Fonseca, F.; Suárez, J. Oleoylethanolamide Modulates BDNF-ERK Signaling and Neurogenesis in the Hippocampi of Rats Exposed to $\triangle 9-T H C$ and Ethanol Binge Drinking During Adolescence. Front. Mol. Neurosci. 2019, 12. [CrossRef] [PubMed]

102. Yang, L.; Xin, X.; Zhang, J.; Zhang, L.; Dong, Y.; Zhang, Y.; Mao, J.; Xie, Z. Inflammatory pain may induce cognitive impairment through an interlukin-6-dependent and postsynaptic density-95-associated mechanism. Anesth. Analg. 2014, 119, 471-480. [CrossRef]

103. Masciopinto, F.; Di Pietro, N.; Corona, C.; Bomba, M.; Pipino, C.; Curcio, M.; Di Castelnuovo, A.; Ciavardelli, D.; Silvestri, E.; Canzoniero, L.M.T.; et al. Effects of long-term treatment with pioglitazone on cognition and glucose metabolism of PS1-KI, 3xTg-AD, and wild-type mice. Cell Death Dis. 2012, 3, e448. [CrossRef] 